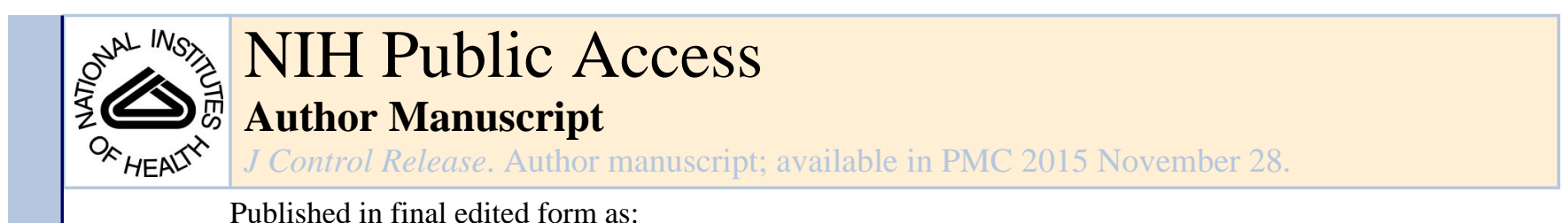

Published in final edited form as:

J Control Release. 2014 November 28; 194: 1-19. doi:10.1016/j.jconrel.2014.08.015.

\title{
Stimuli-Responsive Nanomaterials for Therapeutic Protein Delivery
}

\author{
Yue Lu ${ }^{a, b}$, Wujin Sun ${ }^{a, b}$, and Zhen Gu ${ }^{a, b,{ }^{*}}$ \\ aJoint Department of Biomedical Engineering, University of North Carolina at Chapel Hill and \\ North Carolina State University, Raleigh, NC, 27695, USA \\ benter for Nanotechnology in Drug Delivery and Division of Molecular Pharmaceutics, UNC \\ Eshelman School of Pharmacy, University of North Carolina at Chapel Hill, Chapel Hill, NC, \\ 27599, USA
}

\begin{abstract}
Protein therapeutics have emerged as a significant role in treatment of a broad spectrum of diseases, including cancer, metabolic disorders and autoimmune diseases. The efficacy of protein therapeutics, however, is limited by their instability, immunogenicity and short half-life. In order to overcome these barriers, tremendous efforts have recently been made in developing controlled protein delivery systems. Stimuli-triggered release is an appealing and promising approach for protein delivery and has made protein delivery with both spatiotemporal- and dosage-controlled manners possible. This review surveys recent advances in controlled protein delivery of proteins or peptides using stimuli-responsive nanomaterials. Strategies utilizing both physiological and external stimuli are introduced and discussed.
\end{abstract}

\section{Keywords}

Stimuli-response; nanomaterials; protein/peptide therapeutics; drug delivery; nanomedicine

\section{Introduction}

Proteins, the "engines of life", play the most dynamic and diverse roles among all the macromolecules in human body, including catalyzing biochemistry reactions, controlling cell fates, forming cellular structures, providing tissue scaffolds, and transporting molecules [1]. The history of protein therapeutics usage can be traced back to 1922, when insulin was first purified from bovine pancreas and served as a life-saving daily injection for type 1 diabetes treatment [2]. However, protein therapeutics remained rarely used until the emergence of the first FDA approved recombinant protein therapeutic human insulin 32

(C) 2014 Elsevier B.V. All rights reserved.

‘zgu@email.unc.edu; zgu3@ncsu.edu.

Publisher's Disclaimer: This is a PDF file of an unedited manuscript that has been accepted for publication. As a service to our customers we are providing this early version of the manuscript. The manuscript will undergo copyediting, typesetting, and review of the resulting proof before it is published in its final citable form. Please note that during the production process errors may be discovered which could affect the content, and all legal disclaimers that apply to the journal pertain. 
years ago [3]. Ever since then, the development of protein therapeutics has experienced an explosive growth and protein drugs now play a pivotal role for treating a broad range of diseases, covering cancer, metabolic disorders and autoimmune diseases. To date, more than 130 proteins or peptides have been approved for clinical use by FDA [1]. Compared with small-molecule drugs, protein therapeutics possess several advantages attributed to their highly specific and complex set of functions and superior biocompatibility [1]. Protein therapeutics can also bypass the requirement of permanent or random changes to genetic makeup of the cell, and is therefore a safer alternative compared with gene therapy [4].

Although the last few decades have witnessed significant progresses in the development of protein therapeutics, several challenges still remain to be addressed. Direct delivery of protein therapeutics suffers from their in vitro and in vivo instability, immunogenicity and a relatively short half-life within the body [5]. Also, most proteins are negatively charged at neutral $\mathrm{pH}$, resulting in poor membrane permeability for intracellular delivery [6-8]. Therefore, vast efforts have been put into the design of versatile protein delivery systems for enhancing stability of cargoes, achieving "on demand" precise release and enhancing therapeutic efficacy [9]. In light of this, delivery approaches based on stimuli-responsive smart materials have drawn extensive attentions these years [10]. Stimuli-responsive design is capable of conformational and chemical changes in response to environmental stimuli, and these changes are subsequently accompanied by variations in their physical properties [11]. Such action can not only facilitate release of drug with desirable pharmacokinetics, but also guarantee that drug can be spatiotemporally released at a targeting site. As summarized using a "magic cube" in Fig. 1, based on the distinct functions of target proteins, specific nanomaterials and formulations were engineered and tailed with integration of stimuli triggers. As the central component of a design, stimuli can be typically classified into two groups, including physiological stimuli such as $\mathrm{pH}$, redox potential, enzymatic activities and glucose concentration and external stimuli such as temperature, light, electric field, magnetic field and mechanical force [12]. Other three "faces" of the "magic cube" could involve a variety of diseases, specific targeting sites and bio-inspired designs. We will also incorporate these elements during our discussion.

The emphasis of this review is to introduce and classify recent progress in the development of protein/peptide delivery systems via nano-scale formulations integrated with stimuliresponsive moieties. We will survey representative examples of each stimulus type. Advantages and limitations of different strategies, as well as the future opportunities and challenges will also be discussed.

\section{Physiological stimuli-triggered delivery}

\section{1. $\mathrm{pH}-$ sensitive nanosystems}

Physiological $\mathrm{pH}$ gradients have been widely utilized in the design of stimuli-responsive nanosystems for controlled drug delivery to target locations, including specific organs, intracellular compartments or micro-environments associated with certain pathological situations, such as cancer and inflammation [9]. These delivery systems are typically based on nanostructures that are capable of physical and chemical changes on receiving a $\mathrm{pH}$ signal, such as swelling, charge conversion, membrane fusion and disruption and bond 
cleavage [13]. There are two general strategies to make such $\mathrm{pH}$-responsive nanomaterials. One strategy is to utilize the protonation of copolymers with ionizable groups $[14,15]$. The other strategy is to incorporate acid-cleavable bonds. [16-20]. Adopting these two fundamental mechanisms, researchers have developed numerous $\mathrm{pH}$-responsive nanomaterials to achieve controlled delivery of protein/peptide therapeutics at both cellular and organ level [21]. At cellular level, $\mathrm{pH}$-responsive nanomaterials have been designed to escape acidic endo-lysosomal compartments and lead to cytoplasmic drug release [22, 23]. At organ level, $\mathrm{pH}$-responsive oral delivery systems for controlled delivery of proteins and peptides have been developed for differential drug uptake along the gastrointestinal tract $[24,25]$. Herein, we will introduce recently developed approaches for intracellular delivery and oral delivery. The relevant systems covered in this manuscript are summarized in Table 1 .

\subsection{1. $\mathrm{pH}-$-responsive nanosystems for intracellular protein/peptide delivery-}

After endocytosis, rapid endosomal acidification occurs due to a vacuolar proton ATPasemediated proton influx [26]. As a result, the $\mathrm{pH}$ levels of early endosomes, sorting endosomes, and multivesicular bodies drop rapidly to $\mathrm{pH}<6.0$ [27]. The process of endosomal acidification can be harmful to the cargo molecules, especially macromolecules such as DNA, small interfering RNA (siRNA) and proteins. However, endosomal acidification can also be used as a trigger for endosomal escape and cargo release. As the most studied stimuli-responsive mechanism, $\mathrm{pH}$-triggered intracellular drug release has been extensively investigated and applied in the development of intracellular protein delivery system. $\mathrm{pH}$-responsive protein/peptide delivery systems utilizing various formulations including micelles, liposomes, polymersomes, protein nanocapsules and inorganic nanoparticles such as mesoporous silica nanoparticles (MSNs) have been developed.

Utilizing the above mentioned $\mathrm{pH}$ reduction, Kataoka and co-workers developed an intracellular protein delivery strategy based on charge-conversional polyionic complex (PIC) micelles [28, 29]. The core-shell structured nanomicelles were prepared via electrostatic interactions between diblock copolymers, which were endued with both a neutral poly(ethylene glycol) (PEG) block and an ionic poly(amino acid) block, and their counterions. Equine heart cytochrome c $(\mathrm{CytC})$, a cationic protein, was reversible conjugated with citraconic anhydride and cis-aconitic anhydride to increase charge density and eventually invert surface charge. The modified $\mathrm{CytC}$ was then mixed with a cationic block copolymer, PEG-poly[ $N$ - $\left\{N^{\prime}\right.$-(2-aminoethyl)-2-aminoethyl $\}$ aspartamide] (PEG$\mathrm{pAsp}(\mathrm{DET}))$ to form PIC micelles. The PIC micelles remained stable at physiological $\mathrm{pH}$ ( $\mathrm{pH}$ 7.4), while rapidly disintegrated at $\mathrm{pH} 5.5$ based on a charge-conversional principle. Controlled endosomal release of CytC was confirmed in human hepatoma cell line (HuH-7). The researchers continued to apply this system to deliver bioactive immunoglobulin G ( $\operatorname{IgG})$, antibody with superior selectivity towards its corresponding antigen, into the cytoplasm of HuH-7, demonstrated the potential of this delivery strategy for intracellular imaging and controlled delivery.

Liechty et al. demonstrated the ability of a $\mathrm{pH}$-sensitive phenylalanine derivatized polymer to deliver Apoptin protein into mammalian cells [30]. In this design, hydrophobic Lphenylalanine were grafted onto the carboxylic acid moieties along the backbone of poly(L- 
lysine $i$ so-phthalamide) with a stoichiometric substitution degree of $75 \mathrm{~mol} \%$ (designated as PP-75). [31] The resulted polymer with both hydrophobic side chains and ionisable carboxyl groups would experience conformational change from extended state to collapsed globular state upon $\mathrm{pH}$ reduction (decreased to below its $p \mathrm{~K}_{\mathrm{a}}$ ). Apoptin, the cargo protein, was used in the form of a fusion protein with maltose binding protein (MBP) to enhance solubility. Evidenced by the results of flow-cytometry experiments and mean fluorescence, both the proportion of cells with internalized PP-75-FITC and amount of internalized PP-75-FITC increased with polymer concentration. In vitro, MBP-Apoptin spontaneously forms soluble, non-covalent, globular complexes with an approximate $80 \mathrm{~nm}$ diameter. Attributed to the $\mathrm{N}$ terminal portion of Apoptin and stabilized by hydrophobic interactions, these complexes were composed of 30 40 MBP-Apoptin subunits, and had estimated molecular weight of approximately $2.5 \pm 0.3 \mathrm{MDa}$. The ability of PP-75 to facilitate delivery of fluorescent MBPApoptin conjugated with Alexa Fluor 647 (MA-AF647) to Saos-2 cells was examined via flow-cytometry. Complex dissociation is likely due to intercalation and solubilization of multimeric MBP-Apoptin globules by PP-75, enabling the migration of individual MBPApoptin subunits through the gel. Preliminary research has been conducted to confirm MBPApoptin activity delivered by PP-75. When MBP-Apoptin and PP-75 were delivered in vivo to Saos-2 cells, flow-cytometry analysis showed an approximately $30 \%$ increase of cell population in the mid-apoptotic state, as compared to either MBP-Apoptin or PP-75 alone. $\mathrm{Hu}$ et al. utilized pH-responsive cross-linked PDEAEMA-core/PAEMA-shell particles for intracellular delivery of membrane-impermeable macromolecules, including ova protein, influenza A, and siRNA [32]. These particles were designed to physically segregate the function of cell/drug binding mediated by the particle shell from the function of endolysosomal disruption mediated by the core. Cationic particles with a shell containing primary amines and a core composed of cross-linked poly (diethylaminoethyl methacrylate) (PDEAEMA) were shown to elicit highly efficient endolysosomal disruption via the "proton sponge" effect while exhibiting minimal cytotoxicity. In their studies, Hu et al. demonstrated that proteins with net negative charge could be adsorbed to the cationic shell of $\mathrm{pH}$-responsive core-shell particles, allowing cross-presentation to antigen-specific $\mathrm{CD}^{+}$ T-cells. Cytosolic delivery of protein antigens by these materials dramatically lowered the dose of antigen required to elicit naïve $\mathrm{CD}^{+} \mathrm{T}$-cell priming by DCs by at least $\sim 100$-fold compared to soluble antigen uptaken by DCs.

Giannotti and co-workers reported the synthesis of functional trimethyl chitosan (TMC)based polyelectrolyte complex (PEC) nanocarriers for the lysosomal enzyme R-GAL and prepared the assembly via simple aqueous solution mixing and ionotropic gelation [33]. According to atomic force microscopy (AFM) results, these polyelectrolyte nanoparticles were stable and active under physiological conditions and able to release the loaded enzymes at acidic pH. Gu et al. utilized layer-by-layer assembly of PADH (tertiary amine and hydrazide grafted polyaspartamide) and PACA (carboxyl and aldehyde grafted polyaspartamide) on silica spheres to prepare biodegradable shell cross-linked nanocapsules for protein delivery [14]. Both of the polyaspartamide derivatives are protein-like structured polymers obtained by aminolysis reaction of polysuccinimide which are water-soluble and biodegradable. Bovine serum albumin (BSA) was used as a model protein, and BSA encapsulated nanocapsules were prepared through a three-step procedure: i) layer-by-layer 
assembly of PADH and PACA on the surface of protein-entrapped amino-functionalized silica spheres; ii) hydrazone cross-linking and iii) removal of silica core. BSA release exhibited a pH-dependent behavior: BSA release rate increased significantly as the ambient $\mathrm{pH}$ dropped from the physiological $\mathrm{pH}$ to acidic $\mathrm{pH}$. Further cell viability study demonstrated that the shell cross-linked nanocapsules exhibited good biocompatibility.

Another facile yet delicate approach to achieve controlled protein release upon $\mathrm{pH}$ trigger is to utilize the cargo protein itself as a vehicle. Yan and co-workers reported an intracellular protein delivery system based on a nanocapsule with a single-protein core and a thin permeable polymeric shell (Fig. 2) [34]. Simply put, they covalently linked polymerizable vinyl groups to the protein core. And each protein core was wrapped in a thin polymer shell via subsequent polymerization in an aqueous solution containing monomers and crosslinkers. The degradability of the polymer shell was a result of the degradable crosslinkers, and the surface charge of the nanocapsule could be precisely regulated via tuning the ratio of the monomers (cationic monomers versus neutral monomers). The asprepared nanocapsules displayed a positive surface charge, which was desirable for cellular uptake. A notable advantage of this approach is that the single-protein core here can be chosen from a vast library of proteins, thus, this platform offers a general approach for the controlled delivery of a wide range of proteins. In this specific study, the researchers demonstrated successful delivery of enhanced green fluorescent protein (EGFP), horseradish peroxidase (HRP), BSA, superoxide dismutase (SOD) and caspase-3 (CAS). The researchers further developed this design principle and applied it in the synthesis of a triple-enzyme nanocomplex via DNA-directed assembly and nano-encapsulation [35]. The synthesis of this triple-enzyme nanocomplex was achieved by adopting a three step procedure. A DNAinhibitor scaffold linked with three inhibitors specific for the three enzymes was first formed, and the construction of triple-enzyme complex was realized based on the specific binding between the enzymes and the inhibitors. A polymer shell was then formed via in situ polymerization and the DNA-inhibitor scaffold was removed. Utilizing this approach, the researchers achieved controlled delivery of alcohol oxidase and catalase in order to reduce blood alcohol levels, which displayed potential as an alternative antidote and prophylactic for alcohol intoxication.

MSNs are appealing carriers for delivery of various biomolecules due to their excellent biocompatibility and stability [36]. Compared with other controlled protein delivery systems, using MSNs as intracellular protein delivery carriers has several superiorities: i) High protein-loading capacity can be achieved with the large pore volumes $\left(>1 \mathrm{~cm}^{3} / \mathrm{g}\right)$ of MSNs. ii) The chemically and mechanically stable inorganic oxide framework of MSNs protects the cargo protein from exposure to harmful species. iii) It has been previously proved that MSNs are capable of escaping endolysosomal entrapment. MSNs functionalized with hydrophobic or acid labile moieties were recently employed to transport proteins into cells [37]. Wu et al. prepared aldehyde-displaying silica nanoparticles (MSN-aldehyde) containing lysosome activatable rhodamine-lactams for controlled protein delivery via lysosomal acidity-triggered release [38]. The MSN-aldehyde nanocomposites were sitespecifically embodied into lysosomes of HepG2, HeLa and L929 cells where the loaded protein cargoes, including arginase and green fluorescent protein, were released through 
lysosomal acidity-mediated hydrolysis of the imine cross-linkages. The released proteins escaped from lysosomes into cytosol where arginase efficiently induced autophagy of the host cells. Slowing and co-workers synthesized and characterized a MCM-41-type MSN material with a large pore diameter $(5.4 \mathrm{~nm})$ [39]. Cell-membrane-impermeable protein cytochrome $c$ was loaded as a model protein and its uptake and release profiles were investigated. The enzymatic activity of the pore-released protein was analyzed and compared with that of the native cytochrome $c$ in physiological buffer solutions in order to examine any possible harmful effects caused by encapsulation. The test results showed identical kinetics of the two enzyme-catalyzed reactions, indicating the practicality of this MCM-41-type MSN material in intracellular protein delivery.

\subsection{2. $\mathrm{pH}$-responsive nanosystems for oral protein/peptide delivery-Each} segment of the gastrointestinal tract maintains its own characteristic $\mathrm{pH}$ level, from the acidic stomach lumen ( $\mathrm{pH} \mathrm{1-3)} \mathrm{for} \mathrm{digestion} \mathrm{[40],} \mathrm{to} \mathrm{the} \mathrm{alkaline} \mathrm{duodenum} \mathrm{and} \mathrm{ileum}(\mathrm{pH}$ 6.6-7.5) for the neutralization of chyme [41, 42]. Oral delivery is an attractive drug delivery route for its convenience and patient compliance. However, orally-delivered drugs are exposed to strong gastric acid and presystemic enzymatic degradation, resulting in poor systemic exposure. Efficient oral delivery of proteins and peptides are hindered by three major barriers, including the enzymatic barrier, the mucus gel layer barrier and the absorption barrier. The development of smart oral delivery carriers capable of protecting cargo protein from digestion while releasing the loaded proteins at target site is therefore highly desirable.

Gao et al. developed a biodegradable and $\mathrm{pH}$-sensitive hydrogels composed of four types of $\mathrm{pH}$-sensitive polyacrylic acid derivatives (PAAD) and a biodegradable poly(L-glutamic acid) (PGA) crosslinker for oral delivery of proteins and peptides [43]. In this work, insulin was loaded into the hydrogels as a model protein. The results of the investigations of swelling and biodegradation behaviors indicated that the hydrogels based on PAAD with higher hydrophobicity exhibited the lower swelling ratios and less biodegradation in the condition of mimicking stomach environment, while the hydrogels showed the higher swelling ratios and more biodegradation in the condition of mimicking intestine environment. Following oral administration of insulin-loaded hydrogels to streptozotocininduced diabetic rats, significantly hypoglycemic effect was observed within $7 \mathrm{~h}$. Lin and co-workers synthesized $\mathrm{pH}$-responsive nanoparticles (NPs) composed of chitosan (CS) and poly- $\gamma$-glutamic acid ( $\gamma$-PGA) blended with tripolyphosphate (TPP) and $\mathrm{MgSO}_{4}$ (multi-ioncrosslinked NPs) and investigated their effectiveness in oral delivery of insulin [44]. The NPs were used to encapsulate insulin when $\mathrm{pH}<6$ and release it at higher $\mathrm{pH}$ by the deprotonization of chitosan and destabilization of NPs.

Oral delivery using nanoparticles is often highly limited by their low transportation efficiency across the intestinal epithelium. In order to address this, Pridgen and co-workers developed Fc-targeted nanoparticles and evaluated their potential in oral delivery of insulin [45]. The surface of PLA-PEG NP was modified with IgG Fc fragments to target the neonatal $\mathrm{Fc}$ receptor $(\mathrm{FcRn})$, which played an essential role in the transport of $\operatorname{IgG}$ across epithelial barriers. Under the acidic environment of the intestine, IgG Fc on the NP surface bond to FcRn on the apical side of epithelial cells. Fc modified NPs then went across the 
epithelial cell through the FcRn transcytosis pathway. Upon exocytosis, Fc modified NPs dissociated from FcRn under physiological $\mathrm{pH}$, the NPs were thus set free and eventually entered systemic circulation. In this study, enhanced transepithelial transportation was observed both in vitro and in vivo.

\subsection{Redox-responsive nanosystems}

Glutathione (GSH) is a tripeptide found at 2 to 3 orders higher level (approximately 2-10 $\mathrm{mM}$ ) in the cytosol than the extracellular fluids (approximately 2-20 $\mu \mathrm{M}$ ) [46], rendering the relatively low intracellular redox potential. Thus, redox-responsive vehicles are mostly intended to disassemble and release drugs in the cytosol. Disulfides are degradable in presence of various reducing agents, including GSH, while the resulting thiol groups can reversibly reform disulfide bonds upon oxidation. [47] This thiol-disulfide exchange offers opportunity to achieve programmable drug release utilizing redox potential as trigger. [48] Attributed to the reversible characteristic of thiol-disulfide chemistry, disulfide bonds can be incorporated into either the polymer backbone or the crosslinkers in order to design redoxresponsive nanomaterials.

Zhao et al. reported the preparation of redox-responsive single-protein nanocapsules for intracellular protein delivery [49]. In this delivery system, target protein was non-covalently encapsulated into a positively-charged polymeric shell interconnected by disulfidecontaining crosslinkers via in situ interfacial polymerization. Cell-free assays were conducted to demonstrate the dissociation of the polymeric shell under reducing conditions and subsequent release of protein in the presence of GSH. The nanocapsules were proved to be capable of validly releasing protein cargoes into cytosol. Caspase 3 (CP-3) was delivered and hence induced apoptosis in a variety of human cancer cell lines, including HeLa, MCF-7 and U-87 MG, using these nanocapsules as carriers. Recently, Zhao and co-workers continued to report a core-shell structured redox-responsive polymeric protein nanocapsule for intracellular delivery of recombinant maltose-bindingprotein fused apoptin (MBP-APO) (Fig. 3) [50]. In this delivery system, MBP-APO was reversibly encapsulated in a positively charged, water soluble polymer shell and was released in the reducing environments of cytoplasm.

Zheng et al. designed and synthesized biodegradable redox-responsive nanocapsules adopting the layer-by-layer technique with poly (L-aspartic acid) and chitosan as vehicles for transmucosal delivery of proteins and peptides [51]. TEM images showed that intact nanocapsules were obtained and the shell of the nanocapsules was about $40 \mathrm{~nm}$. Mucoadhesion test indicated that the adsorption amount of the mucin could reach up to $96.2 \mu \mathrm{g}$ per $2 \mathrm{mg}$. The cell viability test demonstrated that all types of nanocapsules had good cytocompatibility and the cell viability was above $90 \%$. As a model protein, insulin was loaded into the nanocapsules, and with a loading efficiency about 5\%. The release amount of insulin could be regulated by the levels of GSH.

\subsection{Enzyme-responsive nanosystems}

Enzymes play a central role in biochemical processes, and therefore are important targets for drug development [52]. When an enzymatic activity is associated with a particular tissue or 
an enzyme level is upregulated at the target site, nanomaterials can be designed to deliver drugs via specific enzymatic conversion. Compared with delivery approaches utilizing other internal or external stimuli, such as temperature, $\mathrm{pH}$, and light, the enzyme-based approach represents an elegant biocompatible method of both high sensitivity and selectivity for programmed delivery of proteins to the enzyme-overexpression target sites [53], which has led to growing interest in developing enzyme-responsive nanomaterials as smart protein delivery systems. In the past few years, considerable progresses have been made in the field of enzyme-responsive protein delivery systems.

Biswas et al. designed a biomimetic protein delivery system, where cargo proteins were encapsulated in a nano matrix crosslinked by bisacrylated peptides with a specific sensitivity towards furin [54]. The development of this furin-degradable construction was inspired by the various and essential natural rules of furin, a ubiquitous intracellular protease expressed in all eukaryotic organisms and many mammalian cells. Furin is a transmembrane protein cycling between the surface and the trans Golgi network during substrate processing. [55] Elevated furin expression is associated with a series of diseases, including cancer, thus can be utilized as a target for drug delivery towards various cell lines, especially cancerous cell lines. A general mechanism adopting a facile two-step procedure was developed for the delivery of a wide sort of functional proteins: positively charged monomer ( $\mathrm{N}$-(3aminopropyl) methacrylamide (APMAAm)), neutral monomer (acrylaminde (AAM)), and furin-cleavable bisacrylated peptide crosslinkers were first enriched around protein surfaces via electrostatic and hydrogen bonding interactions, followed by the formation of a thin polymer layer around protein surfaces through in-situ free-radical polymerization, leading to the formation of protein nanocapsules (NCs) with controlled composition. The surface charge of the nanocapsule was controlled via regulating the ratio of the positive-charged and the neutral monomers. The sizes of resulting protein-containing NCs were within the range of 10 to $15 \mathrm{~nm}$. And these NCs were positively charged, favorable for intracellular uptake. Furin-triggered protein release from the NCs was quantified via the enzyme-linked immunosorbant assay (ELISA) using enhanced green fluorescence protein (eGFP) as a model protein. No significant protein release was observed over $24 \mathrm{~h}$ in absence of furin, conversely, upon the addition of 4 unit furin, a rapid release of eGFP was observed and $\sim 80 \%$ of the encapsulated eGFP was released before reaching the plateau level. Utilizing this nanoplatform, the researcher delivered both cytosolic and nuclear proteins, such as EGFP, CP3, BSA and the transcription factor Klf4, in active forms to different of cell lines. Wen et al. reported an enzyme-responsive delivery platform with controlled-releasing capability and specificity based on protein nanocapsules [56]. When exposed to proteases, the peptide crosslinkers surrounding the protein surface were cleaved, releasing their protein cargo. Specific enzyme-degradation of nanocapsules could be achieved by picking particular enzymes and utilizing peptide crosslinkers with specific sequences. In their research, vascular endothelial growth factor (VEGF) for promoting angiogenesis was used as a model protein [57]. Since matrix metalloproteinases (MMP) [58] and serine proteases, such as plasmin, are generally upregulated in diseased or injured tissues [59, 60], they were chosen as the enzyme trigger to demonstrate the controlled release of VEGF from their nanocapsules. 
Aimetti et al. presented a method of fabricating enzyme-responsive PEG hydrogels for controlled protein delivery via thiol-ene photopolymerization [61]. Thiol-ene photopolymerization is based on the radical catalyzed addition of a thiol to a vinyl functional group. At the presence of light, a photoinitiator abstracts a hydrogen atom from a thiol and form a thiyl radical which can add across a carbon-carbon double bond. The subsequent propagation-chain transfer events result in a step-growth mechanism. Based on this mechanism, highly cross-linked polymer networks are formed when multifunctional monomers with an average functionality greater than two are utilized [61, 62]. In order to treat inflammation locally, they designed a PEG hydrogel system with human neutrophil elastase (HNE) sensitive peptide crosslinkers synthesized via thiol-ene photopolymerization rendering the gel degradable at sites of inflammation. Protein therapeutics physically entrapped within the network would be selectively released upon exposure to HNE. The controlled delivery of a model protein, BSA, based on this PEG hydrogel system was demonstrated. Thornton and co-workers functionalized Amino-functionalized poly (ethylene glycol acrylamide) (PEGA) hydrogel particles with peptide actuators that cause chargeinduced swelling and cargo release upon exposure to enzyme stimuli [63]. The peptide actuators here were designed based on both the specificity of the target enzyme and the charge properties of the to-be released protein cargo, thereby allowing for tunable release profiles. Fluorescently labelled albumin, avidin and proteins of similar size but opposite charge were released at a rate that was regulated by the peptide actuator linked to the polymer carrier, exhibiting a highly controlled release mechanism. In this work, release profiles were examined using a combination of fluorescence spectroscopy of the solution and two-photon fluorescence microscopy in order to analyze enzymatically triggered molecular events within hydrogels during the initial stages of protein release.

Jiang et al. recently reported an enzyme-responsive gel-liposome-mediated delivery system and achieved programmed co-delivery of tumor necrosis factor-related apoptosis inducing ligand (TRAIL) and small-molecule anticancer drug Dox (Fig. 4) [64]. The core-shell structured nano-vehicle was designed to have a cell-penetrating peptide (CPP, R8H3) modified liposome (R8H3-L) core for Dox loading and a hyaluronic acid (HA) based crosslinked shell for protein encapsulation (designated Gelipo). This smart controlled drug delivery system underwent sequential trigger-responsive mechanisms in the tumor microenvironment, leading to precise release of protein and small-molecule cargoes at different target sites. First, hyaluronidase (HAase), which was proved to be highly expressed in tumor area, promoted the degradation of the HA shell and released the encapsulated TRAIL, which then bond to the plasma membrane and induced apoptosis. The exposed inner core subsequently entered tumor cell and located into endo-lysosomes. Consequent Dox release was then achieved with the aid of R8H3. The synergistic antitumor efficacy of TRAIL/Dox-Gelipo was thoroughly evaluated with both in vivo and in vitro assays. HAasetreated TRAIL/Dox-Gelipo, with concentration ratio fixed at $2 \mathrm{ng} / \mathrm{mL}$ TRAIL and 100 $\mathrm{ng} / \mathrm{mL}$ Dox, induced a higher than $80 \%$ apoptosis ratio on MDA-MB-231 cells, which was prominent compared with the $36.48 \%$ of free TRAIL ( $2 \mathrm{ng} / \mathrm{mL}$ ) and $38.52 \%$ of Dox-R8H3$\mathrm{L}(100 \mathrm{ng} / \mathrm{mL})$. The researchers then investigated the in vivo antitumor efficacy of TRAIL/ Dox-Gelipo using MDA-MB-231 tumor-xenograft mouse models. The Dox amount in tumor tissues was increased by 5.72- and 2.70-fold, respectively, using Gelipo as carrier 
instead of Dox solution and Dox-R8H3-L. Also, a notable enhanced effect on tumor inhibition was observed after TRAIL/Dox-Gelipo treatment.

\subsection{Glucose-responsive insulin release}

Diabetes is a disorder of glucose regulation, which is performed by an accumulating of blood glucose [65]. According to data from International Diabetes Federation, in 2013, there are 382 million children and adults throughout the world suffering from diabetes, and by 2035, this number will rise to 592 million [66]. It has become one of the top health concerns of our time. So far, the major treatment of this disease has been insulin injection together with diet restriction, which is both inconvenient and painful, resulting in a huge desire for an alternative treatment which can directly response to blood glucose levels and achieve a noninvasive and continued insulin administration [67]. Therefore, glucose-responsive based closed-loop platforms have attracted more and more attention in the recent decades. Three typical strategies have been developed for glucose-responsive insulin delivery systems (GRIDS) [68]: incorporation of glucose oxidase (GOx), glucose-binding proteins and boronic acids as glucose-sensitive moieties. We will briefly analyze some recently developed GRIDS.

2.4.1 Glucose oxidase based Insulin delivery-GRIDS based on GOx are one of the most studied glucose-responsive systems that have been thoroughly explored in the past few decades. These GRIDS are typically prepared via the combination of GOx and $\mathrm{pH}-$ responsive hydrogel backbones. GOx converts glucose into gluconic acid in the presence of oxygen, resulting in a decrease of $\mathrm{pH}$, which triggers the swelling or deswelling behavior of the $\mathrm{pH}$-sensitive backbones, contributing to the controlled release of insulin. In 2002, Guiseppi-Elie et al. reported a glucose-triggered insulin delivery system based on hydrogels containing GOx and insulin [69]. GOx was entrapped inside the network of the amphiphilic, pH-responsive membranes (synthesized via the copolymerization of hydroxyethyl methacrylate, dimethylaminoethyl methacrylate and 3-trimethoysilypropyl methacrylate) via UV polymerization, contributing to the glucose-responsiveness of the system. Insulin loading was achieved via either gel entrapment or equilibrium partitioning.

Gu et al. developed a novel glucose-triggered release strategy for the self-regulated insulin delivery via an injectable and acid-degradable polymeric network (Fig. 5) [70]. In this work, surface-modified dextran (designated $m$-dextran) was utilized as an acid-degradable and biocompatible matrix material. Dextran nanoparticles coated with chitosan (positively charged) and alginate (negatively charged) were prepared adopting double emulsion method, respectively. The cohesive gel-like nano-network here was formed via electrostatic interaction between oppositely charged dextran nanoparticles loaded with insulin and GOx. In the hyperglycemic state, this porous architecture would dissociate and subsequently lead to the release of insulin as a result of the catalytic conversion of glucose into gluconic acid. Based on in vitro studies, pulsatile insulin release was achieved in response to glucose concentrations. The researchers then extended their investigations to in vivo systems by applying this degradable nano-network in type 1 diabetic mice. According to the in vivo studies, a single injection of this reported nano-network was able to stabilize blood glucose levels within the normoglycemic state for up to 10 days. This novel insulin delivery nano- 
network based on glucose oxidase has showed a great potential in the development of smart insulin delivery systems and is a promising strategy in self-regulated and long-term diabetes therapy. Gu et al. also developed an injectable glucose-responsive system based on enzyme nanocapsule-integrated $\mathrm{pH}$-responsive microgels [71]. This glucose-responsive insulin delivery platform, prepared via a facile one-step electrospray procedure, was composed of a $\mathrm{pH}$-responsive chitosan matrix, enzyme nanocapsules, and recombinant human insulin. Upon being exposed to hyperglycemic environment, GOx encapsulated in nanoparticles began to converting glucose into gluconic acid, which caused the protonation of the chitosan network, and eventually led to the swelling of the microgel. This system was then further adjusted to achieve different insulin release rates under different blood sugar concentrations. In vivo studies carried out in streptozotocin-induced diabetic mice demonstrated the possibility of using this smart system in glucose regulation for diabetes therapy.

2.4.2 Glucose-binding proteins based insulin delivery-There are three major classes of glucose-binding proteins (apo-enzymes, lectins and a family of proteins recently found in certain bacteria), among which lectins are most used in the development of GRIDS. Lectins are sugar-binding proteins which are highly specific due to their sugar moieties [72]. The first lectin that could be purified on a large scale and achieved on a commercial basis was concanavalin A (ConA) and the first GRIDS based on ConA was developed by Brownlee and Cerami in 1979 [73]. ConA is a saccharide-binding lectin which displays reversible affinity for non-reducing $\mathrm{a}_{-\mathrm{D}}$-mannose, $\mathrm{a}_{-\mathrm{D}}$-glucose, $\mathrm{N}$-acetyl-D-glucosamine and polysaccharide with unmodified hydroxyl groups at C-3, C-4, and C-6 [74]. In the native state of ConA, one molecule binds two metal atoms: one $\mathrm{Ca}^{2+}$ and one transition metal ion, usually $\mathrm{Mn}^{2+}$. The binding site for the sugar is adjacent to the metal atoms. Then, in the active state of ConA, four molecules join together to form a functional aggregate with four binding sites. Such a specific structure of ConA aggregate is capable of inducing affinity gelation of polysaccharide or other polymers that contain glucose moieties. Free glucose can seize the specific binding sites of ConA-polymer complex, leading to the dissociation of the complex and thus forming glucose-responsive systems [75, 76].

Tanna and co-workers developed a glucose-responsive gel formulation, which contained ConA and specific polysaccharides for the controlled delivery of insulin [77]. The gel here was synthesized through the covalent coupling to two structurally different carbomers (Carbopol 934P and Carbopol 941P) achieved by using the carbodiimide chemistry described by Tanna et al. in 2001 [78]. The gel was proved to be glucose-sensitive and could be triggered repeatedly by the stimulus of glucose. Their study showed the possibility to formulate glucose-responsive gels with covalently coupled carbomer carriers with distinct structures. Nie et al. prepared glucose-responsive hydrogels based on methacrylate derivatives of dextran and ConA and investigated its capability in self-regulated insulin delivery [79]. The results showed that the insulin release was dependent on the glucose concentration. The glucose sensitivity, which could be regulated by the degree of substitution (DS) of the dextran methacrylate derivative, was reversible. The bioactivity of released insulin was also studied, and the results demonstrated that the activity of insulin remained unchanged. 
2.4.3 synthetic boronic acids based Insulin delivery-The water-solubility of boronic acids can be regulated by $\mathrm{pH}$ or diol concentration. In aqueous, boronic acids exist in an equilibrium between an undissociated neutral trigonal form and a dissociated anionic tetrahedral form. With the existence of saccharides, the anionic form binds with diols reversibly to form a 5- or 6-membered ring cyclic boronate ester, shifting the above equilibrium towards the anionic form side. This unique behavior of boronic acids can be used to design GRIDS.

Kim and co-workers reported a sugar-responsive insulin delivery system based on polymersomes of polyboroxole block copolymers [80]. In their study, monosaccharideresponsive poly(styreneboroxole) ( $\mathrm{PBOx}$ ) was synthesized from the controlled radical polymerization of a boroxole-containing styrenic monomer adopting the reversible additionfragmentation and chain transfer (RAFT) method. Amphiphilic block copolymers of PBOx, which could self-assemble into polymersomes in water, were then prepared by performing a RAFT polymerization of PBOx together with a PEG-based macro-chain-transfer agent. Polymersomes of these PBOx copolymers could encapsulate water-soluble cargoes such as insulin in their water-filled inner compartment [81]. Kim et al. investigated the controlled insulin delivery ability of these saccharide-responsive polymersomes by encapsulating fluorescein isothiocyanate (FITC)-labeled human insulin within polymersomes and successfully demonstrated that sugar-triggered insulin release under physiologically relevant $\mathrm{pH}$ conditions could be achieved with such a PBOx based polymersome system.

Lin et al. designed and prepared a boronic acid-functionalized MSN-based drug delivery system (BA-MSN) in order to achieve the controlled double release of both cyclic adenosine monophosphate (cAMP), which could activate $\mathrm{Ca}^{2+}$ channels of pancreas beta cells and thus stimulate insulin secretion upon glucose trigger (Fig. 6) [82]. In this delivery model, gluconic acid-modified insulin was immobilized onto the exterior surface of MSN and served as caps to encapsulate cAMP molecules. Their investigation demonstrated that BAMSN could be applied as an efficient co-delivery system for glucose-responsive triggered release of insulin and cAMP.

\section{External stimuli-triggered delivery}

\subsection{Thermal stimuli}

Thermal sensitive polymers are polymers which exhibit a volume phase transition at a certain temperature. Thermal responsive behavior of polymers is generally viewed as a phenomenon governed by the balance of hydrophilic and hydrophobic moieties on the polymer chain [83]. This temperature-responsive character of certain polymers has been often applied in the design of stimuli-responsive delivery systems.

One major class of thermal sensitive materials are temperature-responsive covalently crosslinked hydrogels, which are probably the most extensively studied thermal responsive drug delivery systems. Although there are several different ways to immobilize proteins in gels, the number of these methods which can be adopted in drug delivery systems is rather limited. One commonly used strategy is to mix the cargo molecules with proper monomer, crosslinker and initiator, which then polymerize and form matrix encapsulated with the 
cargo molecules. This method can be modified as adding cargo molecules into the formed polymer and then crosslinked them chemically. The most used protein loading strategy is to utilize the equilibrium swelling of a hydrogel in a protein-containing solution. According to the studies of Gehrke et al., high protein-loading efficiency can also be achieved via partitioning proteins from polymer solutions of low affinity [84]. Thermal-responsive materials are typically materials with properties, such as solubility, displaying a nonlinear relationship with temperature. [85] Thermal sensitive materials hold a sharp transition temperature at which they either become increasingly soluble or insoluble. [86] Polymers become insoluble upon being heated to the transition temperature exhibit a lower critical solution temperature (LCST). The local temperature of the tumor microenvironment is 1-2 ${ }^{\circ} \mathrm{C}$ higher than that of normal tissue, thence thermal responsive polymers will undergo phase change from the hydrophilic extended state to hydrophobic collapsed state upon transported to tumor site. This temperature-triggered phase switch endues thermal-responsive polymers the capability to release drugs when entering tumor sites. Most of the thermal-sensitive polymers used in biomedical applications exhibit LCST behavior [87], while only a few natural polymers display LCST behavior. Zhang et al. reported a chitosan-PEG copolymer based injectable thermo reversible hydrogel for sustained protein release [88]. The hydrogel was prepared via grafting PEG onto the chitosan backbone. This thermo responsive system was then studied for protein delivery, where BSA was chose as model cargo protein. Their study also confirmed that the structure of BSA maintained unchanged after the release. Compared with natural polymers, synthetic polymers display more potential in the development of thermal responsive protein delivery system. The most extensively studied synthetic polymer which displays a thermo responsive character in biomedical applications is poly ( $N$-isopropylacrylamide) (PNIPAm), due to the fact that its LCST is $32{ }^{\circ} \mathrm{C}$, therefore suitable for in situ gelling [89]. Yang and co-workers studied the interactions between proteins and PNIPAAm hydrogels, which were cross-linked using $N, N^{\prime}$ methylenebisacrylamide and displayed a low LCST. Insulin and BSA were chose as model proteins in order to examine the ability of PNIPAAm hydrogels as potential protein delivery carriers. The release of the protein was not complete as a result of the strong interaction between the polymer and the cargo protein [90]. Hu et al. achieved a sufficient concentration of surface-coupled ATRP initiators (the porous polycaprolactone (PPCL)-Br surfaces) via the reaction between hydroxyl groups on the PPCL films (prepared by using PEG as the pore-forming agent) and 2-bromoisobutyryl bromide for the subsequent surface initiated ATRP of NIPAAm [91]. The resultant PNIPAAm-grafted PPCL films possessed an interconnected porous structure and exhibited a low LCST of about $32^{\circ} \mathrm{C}$. The potential of this grafted polymer film as controlled protein delivery system was then demonstrated using BSA as a model protein.

Metal nanoparticles are capable of absorbing energy and generate heat in response to radio frequency (RF), thus can also be utilized in the design and development of thermalresponsive systems. Stanley and co-workers achieved remote regulation of in vivo insulin production by decorating a modified temperature-sensitive channel, TRPV1, with iron oxide nanoparticles (FeNPs) (Fig. 7) [92]. These FeNPs were coated with antibodies and heated in a low-frequency magnetic field, resulting in a temperature rise. Upon the rise of the local temperature, thermal-responsive TRPV1 was triggered to accelerate calcium transport and 
increased insulin gene expression, leading to the synthesis and release of bioengineered insulin.

\subsection{Light}

Among all the stimuli utilized as controlled drug release triggers, light is especially attractive, as it can remotely trigger drug release with extremely high spatial and temporal precision with an on/off switching pulsatile manner [93, 94]. Additionally, in light-triggered delivery systems, release profiles can be regulated via the adjustment of a broad range of parameters, such as wavelength, light intensity, duration of exposure and beam diameter [95].

$\mathrm{TiO}_{2}$ nanomaterials have superior photocatalytic properties and show excellent biocompatibility, therefore, are considered as suitable nanocarriers for light-triggered protein delivery $[96,97]$. Song et al. reported fabrication of an amphiphilic $\mathrm{TiO}_{2}$ nanotubularstructured carrier for protein delivery. The controlled delivery aim was achieved via a hydrophobic cap on the hydrophilic $\mathrm{TiO}_{2}$ nanotube (Fig. 8) [98]. The loading and release efficacy of this delivery system were investigated and demonstrated using horseradish peroxidase (HRP) as model payload. The hydrophobic cap mentioned above prevented uncontrolled leakage of the hydrophilic protein cargo into aqueous environment, and it could then be removed upon exposure to UV signal via exploiting the photocatalytic nature of $\mathrm{TiO}_{2}$ for UV induced chain scission of attached organic monolayers [99], leading to UVtriggered controlled release of protein cargoes. It is yet noteworthy that most proteins such as BSA were not endurable to UV irradiation [100]. Residues such as tryptophan, tyrosine, phenylalanine, and cysteine/cysteine will undergo photoinduced oxidation, thus are the primary targets of photodegradation in proteins. [101] Photooxidation has been recognized as the major contributor of protein degradation and can lead to changes in the primary, secondary, and tertiary structures of proteins. In a recent work, dendritic conjugates have been developed as fluorescent dendritic nanoprobes for an enhanced photostability. [102] Similar principles can be utilized to develop nanocarriers capable of protecting cargo proteins from photoinduced damages. Compared with UV, visible light is less harmful to proteins due to its lower energy. Luo and co-workers developed a visible light responsive protein delivery system assembled through coordinating hydroxyl onto $\mathrm{TiO}_{2}$ nanoparticle [103]. In their work, hemoglobin $(\mathrm{Hb})$ was chosen as a model protein and covalent attached onto the surface of $\mathrm{TiO}_{2}$ nanoparticles utilizing the coordination of 3, 4-dihydroxyl benzoic acid (DB) to the unsaturated coordinative $\mathrm{TiO}_{2}$ ions. $\mathrm{DB}$ formed a charge-transfer complex with $\mathrm{TiO}_{2}$. Controlled release of $\mathrm{Hb}$ could then be achieved via cleavage of the coordination bonds between $\mathrm{DB}$ and $\mathrm{TiO}_{2}$ surfaces triggered by visible light. According to their investigation, the released $\mathrm{Hb}$ still maintained its structure and bio-catalytic activity.

Instead of directly delivering proteins, Schroeder and co-workers chose a different approach by delivering a "protein factory", where the synthesis of proteins could be remotely triggered by UV (Fig. 9) [104]. This lipid based vesicle was filled with amino acids, ribosomes, and plasmid caged with a photolabile protecting group. Upon UV signal, the vesicle began to synthesize proteins with the cell free protein synthesis machinery. GFP and enzymatically active luciferase were produced using this method. In order to evaluate the 
vesicle's ability of protein production in vivo, the particles were injected locally into mice which were later treated with UV or kept untreated. Results of whole body bioluminescence imaging (Fig. 9-C) verified the nanoparticles' capability of spatiotemporally producing active luciferase upon UV trigger.

Near-infrared light (NIR) has also been utilized to achieve controlled delivery. Tang et al. applied silica-coated gold nanorods onto the skin surface as NIR-responsive heat generator, in order to facilitate transdermal protein delivery [105]. NIR irradiations of the mouse skin using both a continuous-wave laser (CW-laser) and a pulsed laser were investigated, separately, using OVA as model protein. The researchers found that in the case of CW-laser, skin temperature rose upon irradiation, causing migration of inflammation cells and induced expression of heat shock protein (HSP70). Pulsed laser, on the other hand, didn't increase skin temperature since the heated area was limited to the stratum corneum, thus skin histology remained unchanged and no HSP70 induction was observed. In both cases, the permeability of protein through the stratum corneum was enhanced due to the photothermal effect of gold nanorods, therefore providing an alternative approach for transdermal protein delivery and vaccination.

\subsection{Electric field}

Electric current has also been utilized to trigger protein/peptide release. There are basically two methods to develop electro-stimulated drug delivery systems.

One approach is to synthesize a $\mathrm{pH}$-sensitive polymer and change the local $\mathrm{pH}$ via regulating the presence or absence of an electric current [106]. Electro stimulus is an indirect trigger, and this electro-responsive drug delivery system is essentially one derivative of $\mathrm{pH}$ responsive delivery systems. A typical class of materials with this kind of indirect electricsensitivity is complex of poly(ethyloxazoline) (PEOx) and poly(methacrylic acid) (PMAA) formed via hydrogen bonding between oxazoline group and carboxylic group. When $\mathrm{pH}$ is below 5.0, PEOx and PMAA form complex and precipitate immediately, while this solidstate complex will dissolve instantly when $\mathrm{pH}$ is above 5.4 [107]. Kwon et al. investigated the phase change of PEOx/PMMA complex towards electric current trigger by attaching the PEOx/PMMA matrix onto platinum cathode. When an electric current was applied, the matrix surface facing the cathode began to dissolve as a result of the increased local $\mathrm{pH}$.

The other way is the transportation of counterions and water molecules in the nondegradable polymer matrix. Relevant electro-responsive hydrogels have long been studied. Back in 1995, Florence et al. reported the electro-responsive behavior of crosslinked hyaluronic acid (HA) [108]. HA is a naturally existing polysaccharide distributed widely throughout connective, epithelial, and neural tissues, which plays a central role in regulating cell growth and renewal. The system they developed showed a pulsatile release of model macromolecules: the hydrogel swelled upon switching off electric field, leading to release of the model macromolecule, and such a release behavior stopped immediately after the reapplication of the electric field. Shim and co-workers prepared semi- and fullinterpenetrating polymer network (IPN) hydrogels composed of poly(vinyl alcohol) and polyethyleneimine and investigated their bending behavior upon electro stimulus [109]. Semi-IPN referred to the IPN where one component of the assembly was crosslinked and the 
other maintained its linear form, and full-IPN referred to the IPN where all polymer chains were crosslinked. The swelling behaviors showed that the swelling ratio of the semi-IPN hydrogels increased with PEI content in the matrix, while that of full-IPN hydrogels displayed a significant decrease by increasing PEI contents. In the water state of the hydrogels, the full-IPN hydrogels contain less free water in comparison with the semi-IPN hydrogels. Murdan et al. investigated the potential of chondroitin 4-sulphate (CS) hydrogels as electro-controlled carrier to delivery protein and peptide [110]. They studied the loading efficiency and release profiles of a CS hydrogel crosslinked with ethylene glycol diglycidyl ether, using three positively charged molecules (vasopressin, aprotinin and lysozyme) and one negatively charged protein (BSA) as model cargo. According to their study, the CS hydrogel displayed the capability to concentrate positively charged compounds while failed to concentrate negatively charged compounds effectively. Also, the loading efficiency increased with the decrease of the molecular size of the cargo molecules. The release of cargoes could be regulated by changing voltage, and protein was not released in the absence of an electrical field, which indicated the potential of this CS hydrogel as electro-responsive protein delivery platform.

\subsection{Magnetic force}

Magnetically guided delivery strategies have great potential in enhancing the therapeutic profile of drugs by increasing their distribution to the target site as well as lowering offtarget interactions. Magnetic targeting is based on two primary elements: a magnetic field source and a magnetically responsive drug carrier [111].

Magnetic nanoparticles are capable of targeting specific sites to kill tumors under the guidance of a magnetic field. Thus, designing nanovehicles based on magnetic nanoparticles is a rather appealing approach in designing controlled protein delivery systems. In order to determine whether mesoporous magnetic hollow nanoparticles (MMHs) can penetrate cell membranes and deliver protein into subcellular compartments, Huang et al. prepared different functionalized MMHs and investigated their intracellular trafficking using BSA as a model protein payload [112]. The MMHs were prepared adopting a reported facile threestep procedure, where negatively charged polystyrene (PS) nanospheres were used as templates and then removed to form the hollow structure [113]. The results indicated that MMHs modified with amino groups (AMMHs) were efficient in protein loading and capable of transporting BSA into the cells and releasing the protein cargo into subcellular compartments, such as cytosol and nucleus. In addition, studies showed that the nanoparticles were biocompatible, and the encapsulated BSA maintained its bioactivity. Chorny and co-workers developed a magnetic force triggered protein delivery system based on magnetically responsive nanoparticles (MNP) prepared via the precipitation of calcium oleate in the presence of magnetite-based ferrofluid [114]. This system displayed great efficiency in the encapsulation of antioxidant enzymes, superoxide dismutase (SOD) and catalase, and also a considerable therapeutic effect via combating a severe oxidative insult in vitro under the guidance of magnetic field. Quantitative assay of cell uptake verified a $71 \pm 4 \%$ internalization ratio of MNP ( $1 \mu \mathrm{g} /$ well) after being treated with magnetic field for 4 hours. The MNP's capability of providing antioxidant protection was assayed by cell 
viability study and demonstrated by the $62 \pm 12 \%$ recovery of HUVEC exposed to hydrogen peroxide at $10 \mathrm{mM}$ concentration for 5 hours.

Cho et al. developed a magnetic switch for the control of cell death signaling. In this work, death receptor 4 (DR4) monoclonal antibodies, which were highly expressed on tumour cells, were conjugated to magnetic nanoparticles via a specific antigen-antibody interaction (Fig. 10) [115]. They chose Zinc-doped iron oxide magnetic nanoparticles here for their high saturation magnetization value. When applying a magnetic field to aggregate magnetic nanoparticle conjugated DR4s, the magnetic switch is 'ON', thus promoting apoptosis signalling pathways. The efficacy of the magnetic switch for inducing apoptosis in vivo was evaluated using a zebrafish model. An approximately 3.5-fold morphological alteration in the tail region, which was a visible consequence of apoptosis signaling, confirmed the occurrence of apoptosis after applying a $0.50 \mathrm{~T}$ magnetic field for 24 hours.

\subsection{Mechanical force}

These years, controlled drug applying mechanical force as a trigger has attracted increasing interests. For example, Lee and co-workers developed alginate hydrogels to achieve pulsatile release of vascular endothelial growth factor (VEGF) in response to compressive forces with varying strain amplitudes [116]. Encapsulated cargo protein was released upon compression. And once the strain was removed, hydrogel resumed its initial volume.

Among all kinds of mechanical force, ultrasound has long been utilized in drug delivery area for its simplicity, security, inexpensiveness and real time applications [117]. Recently, Jin et al. reported a novel ultrasound-triggered insulin delivery system based on injectable polymeric nano-network (Fig. 11) [118]. PLGA was chosen as the matrix material and insulin loaded nano-network was prepared using a double emulsion method. Positively charged chitosan and negatively charged alginate were used as surfactants, respectively, in order to prepare oppositely charged nanoparticles. A cohesive nano-network was then developed by mixing the above-mentioned two kinds of oppositely charged nanoparticles. The insulin released from the nano-network displayed a ultrasound-triggered pulsatile profile mainly attributed to cavitation induced by focused ultrasound system (FUS). To fully evaluate the efficacy of this smart insulin delivery system as an alternative diabetes therapy, the reaserchers further extended their investigation to in vivo studies using STZ-induced adult diabetic mice as animal model. FUS was applied to the injection site for $30 \sec 2$ days after nano-network injection, leading to a rapid decrease of blood glucose level. Similar FUS treatment performed on day 4, day 7 and day 10 indicated the potential of this FUS-triggered insulin delivery stragety for sustained long-term insluin delivery.

\section{Dual and multi-stimuli responsive systems}

One appealing strategy that has emerged recently is to fabricate systems with the ability to respond to dual and multiple stimuli, thereby assuring drug release under complex pathological conditions with fine tuned drug release profile to augment therapeutic efficacy $[119,120]$. Considerable variety of nanomaterials responsive to dual and multi-stimuli, such as $\mathrm{pH} /$ temperature, $\mathrm{pH} / \mathrm{redox}, \mathrm{pH} / \mathrm{glucose}, \mathrm{pH} /$ enzyme, dual enzyme, $\mathrm{pH} /$ temperature/ glucose have been developed and studied [120]. Among all the dual and multi-stimuli 
responsive nanomaterials, nanomaterial responsive to both $\mathrm{pH}$ and temperature signals is one of the most studied. Zhang et al. developed smart hydrogels composed of $\mathrm{pH}$-sensitive poly (acrylic acid) (PAA) and temperature-sensitive hydroxypropylcellulose-g-acrylic acid (HPC-g-AA) as protein carriers [121]. With respect to $\mathrm{pH}$ responsiveness, hydrogels with higher HPC-g-AA content resulted in lower equilibrium swelling. Decrease of swelling ratio was observed in the as-prepared hydrogels with the increase of temperature, yet the change was not significant. Although temperature had little influence on the swelling of the hydrogels, it determined the optical transmittance of the hydrogels, which indicated that the HPC parts of hydrogel became hydrophobic when the temperature was above the lower critical solution temperature. In addition, the hydrophilicity of PAA increases with the increase of $\mathrm{pH}$, resulting in a $\mathrm{pH}$-dependent temperature-sensitivity. In vitro protein release experiment was carried out first in artificial gastric juice $(\mathrm{pH}=1.2)$ for $2 \mathrm{~h}$ and then in artificial intestinal liquid $(\mathrm{pH}=6.8)$ for the subsequent $6 \mathrm{~h}$, using BSA as a model protein. The release profiles showed that both HPC-g-AA and AA contents played important roles in the protein cargo release behaviors.

Wang and co-workers reported a triple-responsive protein delivery system prepared via the copolymerization of $\mathrm{pH}$ and temperature-sensitive (2-dimethylamino) ethyl methacrylate (DMAEMA) with glucose-sensitive 3-acrylamidephenylboronic acid (AAPBA) [122]. BSA was selected as a model protein to study the release profiles. The $\mathrm{pH}$, temperature and glucose sensitivities were studied, respectively, and the effect of AAPBA content on the swelling ratio was also investigated. Based on the results of the mentioned studies, it was established that the swelling and protein release behavior of the 'smart' hydrogels were significantly influenced by both $\mathrm{pH} /$ temperature and glucose concentration at physiological $\mathrm{pH}$.

$\mathrm{Gu}$ and co-workers incorporated photolabile caged peptide sequences into an enzymatically degradable polymeric nanocapsule and achieved controlled protein release triggered by enzyme and light (Fig. 12) [123]. This cocoon-like nanocapsule was prepared using a facile one-pot procedure (Fig. 12-A): deposition of monomers and crosslinkers onto the surface of cargo protein through physical adsorption including electrostatic force and van der Waals force followed by formation of polymeric protective shell via in situ free-radical polymerization facilitated by protease-cleavable bisacrolylated short peptide crosslinkers. The peptide crosslinkers began to proteolyze upon exposure to proteases, leading to the enzyme-triggered release of cargo protein. The degradability of the polymeric shell can be controlled by choosing the sequences of peptide crosslinker based on their sensitivity to different kinds of proteases, thus this study actually offered a general approach for the controlled protein delivery to different target sites. Photolabile caged peptide sequences were incorporated into the crosslinkers in order to achieve the spatiotemporally controlled release. In this study, the researchers selected CP3 as a model target protein to demonstrate the effectiveness of the nanocapsule for cytoplasmic delivery. A photolabile o-nitrobenzyl ester moiety $\left(D_{m}\right)$ was conjugated onto the VDEVDTK peptide cross-linker in order to cage the P1 aspartic acid (Fig. 12-D). Upon exposure to UV, Dm was cleaved and exposed P1 aspartic acid, the uncaged peptide cross-linker could then be cleaved by CP3, leading to the dissociation of the polymeric shell. Thus, the dissociation of the polymeric shell and release 
of cargo protein could only be achieved via synergistic effect of UV irradiation and CP3 hydrolysis.

Dual- and multi-responsive nanomaterials capable of targeting complex physiological environment hold great potential in further fine tuning the delivery precision and enhancing the therapeutic efficacy of released proteins and peptides, thence have been aggressively pursued these years. However, to date, these reported dual- and multi-responsive systems are often proof-of principle studies due to difficulty in validating sequential or synergistic effects in complicated in vivo environment. Systemic investigations need to be conducted and enormous efforts are required to be invested before these novel systems can finally be utilized in clinical practice.

\section{Summary and outlook}

As discussed above, nanomaterials sensitive to physiological or exogenous stimuli have been widely applied to delivery therapeutic proteins at the right time and (or) place. Dual and multi-responsive nanomaterials sensitive to combinations of triggers in order to customize more specific delivery have also been developed. Relevant materials can be flexibly assembled into diverse formulations to achieve enhanced efficacy. Table 1 summarizes typical examples of different stimuli-responsive nanosystems reported recently.

Despite remarkable achievements in this field, systems tested in in vivo preclinical models or stepped into the clinical stage remain elusive [124]. There are still several challenges that hamper their translation from the bench to the bedside and need to be essentially addressed. First of all, in order to fully achieve clinical potential, the relationship between precise release of protein cargoes at the exact "responsive" site (location/time) and pharmacokinetics should be coordinated [125]. For example, an effective and efficient intracellular protein delivery tool should make sure the nanocarriers have sufficient period of time to be activated to release cargoes through cellular environmental elements, such as acidic or redox potential. Additionally, for glucose-responsive insulin delivery systems, one challenging issue is to achieve fast response to mimic the function of healthy pancreatic cells [67]. Relevant parameters associated with materials, formulations and target proteins can be further tailored to meet the criteria. Second, the translation is limited by the complexity of formulation design and obstacles in scaling-up of synthesis. Formulations with compromise of a simple but effective architectural design are highly possible to win the chance for clinic. Third, how to achieve sufficient biocompatibility is an intractable issue to be solved. One emerging research theme includes engineering nanomaterials that 1) can highly avoid biological sequestration for reducing immune toxicity; 2) have good biodegradability to eventually eliminate through renal clearance for reducing long-term or whole-body toxicity [126]. Lastly, issues related to the tissue penetration depth and side effects of the exogenous physical stimulus would also need to be solved. Meanwhile, exploring new stimuli, for example, those are closely associated with metabolic levels and have targeting efficacy, can also be highly desirable [127]. 


\section{Acknowledgements}

This work was supported by the Junior Faculty Award of the American Diabetes Association (ADA), grant 550KR51307 from NC TraCS, NIH's Clinical and Translational Science Awards (CTSA) at UNC-CH (1UL1TR001111), the NC State Faculty Research and Professional Development Award, and the start-up package from the Joint BME Department of UNC-CH and NCSU to Z.G.

\section{References}

[1]. Leader B, Baca QJ, Golan DE. Protein therapeutics: a summary and pharmacological classification, Nature reviews. Drug discovery. 2008; 7:21-39. [PubMed: 18097458]

[2]. Banting FG, Best CH, Collip JB, Campbell WR, Fletcher AA. Pancreatic Extracts in the Treatment of Diabetes Mellitus. Canadian Medical Association journal. 1922; 12:141-146. [PubMed: 20314060]

[3]. Ziegler TR, Luo M, Estivariz CF, Moore DA 3rd, Sitaraman SV, Hao L, Bazargan N, Klapproth JM, Tian J, Galloway JR, Leader LM, Jones DP, Gewirtz AT. Detectable serum flagellin and lipopolysaccharide and upregulated anti-flagellin and lipopolysaccharide immunoglobulins in human short bowel syndrome. American journal of physiology. Regulatory, integrative and comparative physiology. 2008; 294:R402-410.

[4]. Ford KG, Souberbielle BE, Darling D, Farzaneh F. Protein transduction: an alternative to genetic intervention? Gene therapy. 2001; 8:1-4. [PubMed: 11402295]

[5]. Pisal DS, Kosloski MP, Balu-Iyer SV. Delivery of therapeutic proteins. Journal of pharmaceutical sciences. 2010; 99:2557-2575. [PubMed: 20049941]

[6]. Lu Y, Yang J, Sega E. Issues related to targeted delivery of proteins and peptides. The AAPS journal. 2006; 8:E466-478. [PubMed: 17025264]

[7]. Gu Z, Biswas A, Zhao M, Tang Y. Tailoring nanocarriers for intracellular protein delivery. Chemical Society reviews. 2011; 40:3638-3655. [PubMed: 21566806]

[8]. Tang R, Kim CS, Solfiell DJ, Rana S, Mout R, Velazquez-Delgado EM, Chompoosor A, Jeong Y, Yan B, Zhu ZJ, Kim C, Hardy JA, Rotello VM. Direct delivery of functional proteins and enzymes to the cytosol using nanoparticle-stabilized nanocapsules. ACS nano. 2013; 7:66676673. [PubMed: 23815280]

[9]. Mura S, Nicolas J, Couvreur P. Stimuli-responsive nanocarriers for drug delivery. Nat Mater. 2013; 12:991-1003. [PubMed: 24150417]

[10]. Kim CS, Duncan B, Creran B, Rotello VM. Triggered nanoparticles as therapeutics. Nano Today. 2013; 8:439-447. [PubMed: 24159362]

[11]. Stuart MA, Huck WT, Genzer J, Muller M, Ober C, Stamm M, Sukhorukov GB, Szleifer I, Tsukruk VV, Urban M, Winnik F, Zauscher S, Luzinov I, Minko S. Emerging applications of stimuli-responsive polymer materials. Nature materials. 2010; 9:101-113.

[12]. Matsumura Y, Maeda H. A new concept for macromolecular therapeutics in cancer chemotherapy: mechanism of tumoritropic accumulation of proteins and the antitumor agent smancs. Cancer research. 1986; 46:6387-6392. [PubMed: 2946403]

[13]. Mo R, Sun Q, Xue J, Li N, Li W, Zhang C, Ping Q. Multistage pH-responsive liposomes for mitochondrial-targeted anticancer drug delivery. Advanced materials. 2012; 24:3659-3665. [PubMed: 22678851]

[14]. Gu X, Wang J, Wang Y, Wang Y, Gao H, Wu G. Layer-by-layer assembled polyaspartamide nanocapsules for $\mathrm{pH}$-responsive protein delivery. Colloids and surfaces. B, Biointerfaces. 2013; 108:205-211.

[15]. Lee ES, Na K, Bae YH. Doxorubicin loaded pH-sensitive polymeric micelles for reversal of resistant MCF-7 tumor. Journal of controlled release: official journal of the Controlled Release Society. 2005; 103:405-418. [PubMed: 15763623]

[16]. Bae Y, Kataoka K. Intelligent polymeric micelles from functional poly(ethylene glycol)poly(amino acid) block copolymers. Adv Drug Deliv Rev. 2009; 61:768-784. [PubMed: 19422866] 
[17]. Bae Y, Fukushima S, Harada A, Kataoka K. Design of environment-sensitive supramolecular assemblies for intracellular drug delivery: polymeric micelles that are responsive to intracellular pH change. Angewandte Chemie. 2003; 42:4640-4643. [PubMed: 14533151]

[18]. Bae Y, Nishiyama N, Kataoka K. In vivo antitumor activity of the folate-conjugated pH-sensitive polymeric micelle selectively releasing adriamycin in the intracellular acidic compartments. Bioconjugate chemistry. 2007; 18:1131-1139. [PubMed: 17488066]

[19]. Wang X, Wu G, Lu C, Zhao W, Wang Y, Fan Y, Gao H, Ma J. A novel delivery system of doxorubicin with high load and $\mathrm{pH}$-responsive release from the nanoparticles of poly (alpha,betaaspartic acid) derivative. European journal of pharmaceutical sciences: official journal of the European Federation for Pharmaceutical Sciences. 2012; 47:256-264. [PubMed: 22522116]

[20]. Zhou L, Cheng R, Tao H, Ma S, Guo W, Meng F, Liu H, Liu Z, Zhong Z. Endosomal pHactivatable poly(ethylene oxide)-graft-doxorubicin prodrugs: synthesis, drug release, and biodistribution in tumor-bearing mice. Biomacromolecules. 2011; 12:1460-1467. [PubMed: 21332185]

[21]. Gao W, Chan JM, Farokhzad OC. pH-Responsive nanoparticles for drug delivery. Molecular pharmaceutics. 2010; 7:1913-1920. [PubMed: 20836539]

[22]. Dominska M, Dykxhoorn DM. Breaking down the barriers: siRNA delivery and endosome escape. Journal of cell science. 2010; 123:1183-1189. [PubMed: 20356929]

[23]. Whitehead KA, Langer R, Anderson DG. Knocking down barriers: advances in siRNA delivery. Nat Rev Drug Discov. 2009; 8:129-138. [PubMed: 19180106]

[24]. Davis SS, Wilding EA, Wilding IR. Gastrointestinal Transit of a Matrix Tablet Formulation Comparison of Canine and Human Data. Int J Pharm. 1993; 94:235-238.

[25]. Rajput G, Majmudar F, Patel J, Thakor R, Rajgor NB. Stomach-specific mucoadhesive microsphere as a controlled drug delivery system. Sys. Rev. Pham. 2010; 1

[26]. Ren DM, Kratz F, Wang SW. Protein Nanocapsules Containing Doxorubicin as a pH-Responsive Delivery System. Small. 2011; 7:1051-1060. [PubMed: 21456086]

[27]. Murphy RF, Powers S, Cantor CR. Endosome Ph Measured in Single Cells by Dual Fluorescence Flow-Cytometry - Rapid Acidification of Insulin to Ph-6. J Cell Biol. 1984; 98:1757-1762. [PubMed: 6144684]

[28]. Lee Y, Ishii T, Cabral H, Kim HJ, Seo JH, Nishiyama N, Oshima H, Osada K, Kataoka K. Charge-conversional polyionic complex micelles-efficient nanocarriers for protein delivery into cytoplasm. Angewandte Chemie. 2009; 48:5309-5312. [PubMed: 19294716]

[29]. Lee Y, Ishii T, Kim HJ, Nishiyama N, Hayakawa Y, Itaka K, Kataoka K. Efficient delivery of bioactive antibodies into the cytoplasm of living cells by charge-conversional polyion complex micelles. Angewandte Chemie. 2010; 49:2552-2555. [PubMed: 20209539]

[30]. Liechty WB, Chen R, Farzaneh F, Tavassoli M, Slater NKH. Synthetic pH-Responsive Polymers for Protein Transduction. Advanced materials. 2009; 21:3910-3914. [PubMed: 22427722]

[31]. Yue Z, Eccleston ME, Slater NKH. Modulation of the $\mathrm{pH}$-responsive properties of poly(l-lysine iso-phthalamide) grafted with a poly(ethylene glycol) analogue. Biomaterials. 2005; 26:63576366. [PubMed: 15913772]

[32]. Hu YH, Atukorale PU, Lu JJ, Moon JJ, Um SH, Cho EC, Wang Y, Chen JZ, Irvine DJ. Cytosolic Delivery Mediated via Electrostatic Surface Binding of Protein, Virus, or siRNA Cargos to $\mathrm{pH}-$ Responsive Core-Shell Gel Particles. Biomacromolecules. 2009; 10:756-765. [PubMed: 19239276]

[33]. Giannotti MI, Esteban O, Oliva M, Garcia-Parajo MF, Sanz F. pH-Responsive PolysaccharideBased Polyelectrolyte Complexes As Nanocarriers for Lysosomal Delivery of Therapeutic Proteins. Biomacromolecules. 2011; 12:2524-2533. [PubMed: 21604696]

[34]. Yan M, Du JJ, Gu Z, Liang M, Hu YF, Zhang WJ, Priceman S, Wu LL, Zhou ZH, Liu Z, Segura T, Tang Y, Lu YF. A novel intracellular protein delivery platform based on single-protein nanocapsules. Nat Nanotechnol. 2010; 5:48-53. [PubMed: 19935648]

[35]. Liu Y, Du JJ, Yan M, Lau MY, Hu J, Han H, Yang OO, Liang S, Wei W, Wang H, Li JM, Zhu XY, Shi LQ, Chen W, Ji C, Lu YF. Biomimetic enzyme nanocomplexes and their use as antidotes and preventive measures for alcohol intoxication. Nat Nanotechnol. 2013; 8:187-192. [PubMed: 23416793] 
[36]. Popat A, Hartono SB, Stahr F, Liu J, Qiao SZ, Lu GQ. Mesoporous silica nanoparticles for bioadsorption, enzyme immobilisation, and delivery carriers. Nanoscale. 2011; 3:2801-2818. [PubMed: 21547299]

[37]. Lim JS, Lee K, Choi JN, Hwang YK, Yun MY, Kim HJ, Won YS, Kim SJ, Kwon H, Huh S. Intracellular protein delivery by hollow mesoporous silica capsules with a large surface hole. Nanotechnology. 2012; 23

[38]. Wu XJ, Wu SQ, Yang L, Han JH, Han SF. Cytosolic delivery of proteins mediated by aldehydedisplaying silica nanoparticles with pH-responsive characteristics. J Mater Chem. 2012; 22:17121-17127.

[39]. Slowing II, Trewyn BG, Lin VSY. Mesoporous silica nanoparticles for intracellular delivery of membrane-impermeable proteins. J Am Chem Soc. 2007; 129:8845-8849. [PubMed: 17589996]

[40]. Dressman JB, Berardi RR, Dermentzoglou LC, Russell TL, Schmaltz SP, Barnett JL, Jarvenpaa KM. Upper Gastrointestinal (Gi) Ph in Young, Healthy-Men and Women. Pharmaceut Res. 1990; 7:756-761.

[41]. Kararli TT. Comparison of the Gastrointestinal Anatomy, Physiology, and Biochemistry of Humans and Commonly Used Laboratory-Animals. Biopharm Drug Dispos. 1995; 16:351-380. [PubMed: 8527686]

[42]. Read NW, Sugden K. Gastrointestinal Dynamics and Pharmacology for the Optimum Design of Controlled-Release Oral Dosage Forms. Crit Rev Ther Drug. 1988; 4:221-263.

[43]. Gao XY, He CL, Xiao CS, Zhuang XL, Chen XS. Biodegradable pH-responsive polyacrylic acid derivative hydrogels with tunable swelling behavior for oral delivery of insulin. Polymer. 2013; 54:1786-1793.

[44]. Lin YH, Sonaje K, Lin KM, Juang JH, Mi FL, Yang HW, Sung HW. Multi-ion-crosslinked nanoparticles with $\mathrm{pH}$-responsive characteristics for oral delivery of protein drugs. J Control Release. 2008; 132:141-149. [PubMed: 18817821]

[45]. Pridgen EM, Alexis F, Kuo TT, Levy-Nissenbaum E, Karnik R, Blumberg RS, Langer R, Farokhzad OC. Transepithelial transport of Fc-targeted nanoparticles by the neonatal fc receptor for oral delivery. Science translational medicine. 2013; 5:213ra167.

[46]. Schafer FQ, Buettner GR. Redox environment of the cell as viewed through the redox state of the glutathione disulfide/glutathione couple. Free Radical Bio Med. 2001; 30:1191-1212. [PubMed: 11368918]

[47]. Kamada J, Koynov K, Corten C, Juhari A, Yoon JA, Urban MW, Balazs AC, Matyjaszewski K. Redox Responsive Behavior of Thiol/Disulfide-Functionalized Star Polymers Synthesized via Atom Transfer Radical Polymerization. Macromolecules. 2010; 43:4133-4139.

[48]. Zhang W, Tichy SE, Pérez LM, Maria GC, Lindahl PA, Simanek EE. Evaluation of Multivalent Dendrimers Based on Melamine: Kinetics of Thiol-Disulfide Exchange Depends on the Structure of the Dendrimer. Journal of the American Chemical Society. 2003; 125:5086-5094. [PubMed: 12708859]

[49]. Zhao MX, Biswas A, Hu BL, Joo KI, Wang P, Gu Z, Tang Y. Redox-responsive nanocapsules for intracellular protein delivery. Biomaterials. 2011; 32:5223-5230. [PubMed: 21514660]

[50]. Zhao MX, Hu BL, Gu Z, Joo KI, Wang P, Tang Y. Degradable polymeric nanocapsule for efficient intracellular delivery of a high molecular weight tumor-selective protein complex. Nano Today. 2013; 8:11-20.

[51]. Zheng C, Zhang XG, Sun L, Zhang ZP, Li CX. Biodegradable and redox-responsive chitosan/ poly(L-aspartic acid) submicron capsules for transmucosal delivery of proteins and peptides. $\mathrm{J}$ Mater Sci-Mater M. 2013; 24:931-939. [PubMed: 23386208]

[52]. de la Rica R, Aili D, Stevens MM. Enzyme-responsive nanoparticles for drug release and diagnostics. Advanced drug delivery reviews. 2012; 64:967-978. [PubMed: 22266127]

[53]. Guo DS, Wang K, Wang YX, Liu Y. Cholinesterase-responsive supramolecular vesicle. J Am Chem Soc. 2012; 134:10244-10250. [PubMed: 22686862]

[54]. Biswas A, Joo KI, Liu J, Zhao M, Fan G, Wang P, Gu Z, Tang Y. Endoprotease-mediated intracellular protein delivery using nanocapsules. Acs Nano. 2011; 5:1385-1394. [PubMed: 21268592] 
[55]. Hajdin K, d'Alessandro V, Niggli FK, Schäfer BW, Bernasconi M. Furin Targeted Drug Delivery for Treatment of Rhabdomyosarcoma in a Mouse Model. PLoS ONE. 2010; 5:1-13.

[56]. Wen J, Anderson SM, Du J, Yan M, Wang J, Shen M, Lu Y, Segura T. Controlled protein delivery based on enzyme-responsive nanocapsules. Adv Mater. 2011; 23:4549-4553. [PubMed: 21910141]

[57]. Gerhardt H, Golding M, Fruttiger M, Ruhrberg C, Lundkvist A, Abramsson A, Jeltsch M, Mitchell C, Alitalo K, Shima D, Betsholtz C. VEGF guides angiogenic sprouting utilizing endothelial tip cell filopodia. The Journal of cell biology. 2003; 161:1163-1177. [PubMed: 12810700]

[58]. Shiomi T, Lemaitre V, D'Armiento J, Okada Y. Matrix metalloproteinases, a disintegrin and metalloproteinases, and a disintegrin and metalloproteinases with thrombospondin motifs in nonneoplastic diseases. Pathology international. 2010; 60:477-496. [PubMed: 20594269]

[59]. Roth D, Piekarek M, Paulsson M, Christ H, Bloch W, Krieg T, Davidson JM, Eming SA. Plasmin modulates vascular endothelial growth factor-A-mediated angiogenesis during wound repair. The American journal of pathology. 2006; 168:670-684. [PubMed: 16436680]

[60]. Syrovets T, Simmet T. Novel aspects and new roles for the serine protease plasmin. Cellular and molecular life sciences: CMLS. 2004; 61:873-885. [PubMed: 15095009]

[61]. Aimetti AA, Machen AJ, Anseth KS. Poly(ethylene glycol) hydrogels formed by thiol-ene photopolymerization for enzyme-responsive protein delivery. Biomaterials. 2009; 30:6048-6054. [PubMed: 19674784]

[62]. Cramer NB, Davies T, O'Brien AK, Bowman CN. Mechanism and Modeling of a Thiol-Ene Photopolymerization. Macromolecules. 2003; 36:4631-4636.

[63]. Thornton PD, Mart RJ, Webb SJ, Ulijn RV. Enzyme-responsive hydrogel particles for the controlled release of proteins: designing peptide actuators to match payload. Soft Matter. 2008; 4:821-827.

[64]. Jiang T, Mo R, Bellotti A, Zhou J, Gu Z. Gel-Liposome-Mediated Co-Delivery of Anticancer Membrane-Associated Proteins and Small-Molecule Drugs for Enhanced Therapeutic Efficacy. Advanced Functional Materials. 2013 n/a-n/a.

[65]. Wu Q, Wang L, Yu H, Wang J, Chen Z. Organization of glucose-responsive systems and their properties. Chemical reviews. 2011; 111:7855-7875. [PubMed: 21902252]

[66]. I.D. Federation. 2013.

[67]. Ran Mo TJ, Di Jin, Tai Wanyi, Gu Zhen. Emerging Micro- and Nanotechnology Based Synthetic Approaches for Insulin Delivery. Chem. Soc. Rev. 2014

[68]. Wu W, Zhou S. Responsive materials for self-regulated insulin delivery. Macromolecular bioscience. 2013; 13:1464-1477. [PubMed: 23839986]

[69]. Guiseppi-Elie A, Brahim SI, Narinesingh D. A Chemically Synthesized Artificial Pancreas: Release of Insulin from Glucose-Responsive Hydrogels. Adv Mater. 2002; 14:743-746.

[70]. Gu Z, Aimetti AA, Wang Q, Dang TT, Zhang Y, Veiseh O, Cheng H, Langer RS, Anderson DG. Injectable nano-network for glucose-mediated insulin delivery. ACS nano. 2013; 7:4194-4201. [PubMed: 23638642]

[71]. Gu Z, Dang TT, Ma M, Tang BC, Cheng H, Jiang S, Dong Y, Zhang Y, Anderson DG. Glucoseresponsive microgels integrated with enzyme nanocapsules for closed-loop insulin delivery. ACS nano. 2013; 7:6758-6766. [PubMed: 23834678]

[72]. Sharon N. Lectins. Scientific American. 1977; 236:108-116. 118-109. [PubMed: 867026]

[73]. Brownlee M, Cerami A. A glucose-controlled insulin-delivery system: semisynthetic insulin bound to lectin. Science. 1979; 206:1190-1191. [PubMed: 505005]

[74]. Edelman GM, Cunningham BA, Reeke GN Jr. Becker JW, Waxdal MJ, Wang JL. The covalent and three-dimensional structure of concanavalin A. Proceedings of the National Academy of Sciences of the United States of America. 1972; 69:2580-2584. [PubMed: 4506778]

[75]. Zion, TC. Glucose-responsive materials for self-regulated insulin delivery. Massachusetts Institute of Technology; 2004. p. 89leaves

[76]. Todd, AZ.; Zion, C.; Ying, Jackie Y. Stimuli-responsive systems for controlled drug delivery. Massachusetts Institute of Technology; 2003. 
[77]. Tanna S, Sahota T, Clark J, Taylor MJ. Covalent coupling of concanavalin A to a Carbopol 934P and 941P carrier in glucose-sensitive gels for delivery of insulin. The Journal of pharmacy and pharmacology. 2002; 54:1461-1469. [PubMed: 12495548]

[78]. Tanna S, Sahota T, Clark J, Taylor MJ. Covalent coupling of concanavalin A to a Carbopol 934P and 941P carrier in glucose-sensitive gels for delivery of insulin. Journal of Pharmacy and Pharmacology. 2002; 54:1461-1469. [PubMed: 12495548]

[79]. Yin R, Tong Z, Yang D, Nie J. Glucose-responsive microhydrogels based on methacrylate modified dextran/concanavalin A for insulin delivery. J Control Release. 2011; 152(Suppl 1):e163-165. [PubMed: 22195824]

[80]. Kim H, Kang YJ, Kang S, Kim KT. Monosaccharide-responsive release of insulin from polymersomes of polyboroxole block copolymers at neutral pH. J Am Chem Soc. 2012; 134:4030-4033. [PubMed: 22339262]

[81]. Tanner P, Baumann P, Enea R, Onaca O, Palivan C, Meier W. Polymeric vesicles: from drug carriers to nanoreactors and artificial organelles. Acc Chem Res. 2011; 44:1039-1049. [PubMed: 21608994]

[82]. Zhao Y, Trewyn BG, Slowing, Lin VS. Mesoporous silica nanoparticle-based double drug delivery system for glucose-responsive controlled release of insulin and cyclic AMP. Journal of the American Chemical Society. 2009; 131:8398-8400. [PubMed: 19476380]

[83]. Heskins M, Guillet JE. Solution Properties of Poly(N-isopropylacrylamide). Journal of Macromolecular Science: Part A - Chemistry. 1968; 2:1441-1455.

[84]. Gehrke SH, Vaid NR, McBride JF. Protein sorption and recovery by hydrogels using principles of aqueous two-phase extraction. Biotechnology and Bioengineering. 1998; 58:416-427. [PubMed: 10099276]

[85]. Abulateefeh SR, Spain SG, Aylott JW, Chan WC, Garnett MC, Alexander C. Thermoresponsive Polymer Colloids for Drug Delivery and Cancer Therapy. Macromolecular Bioscience. 2011; 11:1722-1734. [PubMed: 22012834]

[86]. Schmaljohann D. Thermo- and pH-responsive polymers in drug delivery. Advanced Drug Delivery Reviews. 2006; 58:1655-1670. [PubMed: 17125884]

[87]. Arnott S, Fulmer A, Scott WE, Dea IC, Moorhouse R, Rees DA. The agarose double helix and its function in agarose gel structure. Journal of molecular biology. 1974; 90:269-284. [PubMed: 4453017]

[88]. Bhattarai N, Ramay HR, Gunn J, Matsen FA, Zhang M. PEG-grafted chitosan as an injectable thermosensitive hydrogel for sustained protein release. J Control Release. 2005; 103:609-624. [PubMed: 15820408]

[89]. Schild HG. Poly(N-isopropylacrylamide): experiment, theory and application. Progress in Polymer Science. 1992; 17:163-249.

[90]. Wu JY, Liu SQ, Heng PW, Yang YY. Evaluating proteins release from, and their interactions with, thermosensitive poly (N-isopropylacrylamide) hydrogels. J Control Release. 2005; 102:361-372. [PubMed: 15653157]

[91]. Hu Y, Zhao NN, Li JS, Yang WT, Xu FJ. Temperature-responsive porous polycaprolactonebased films via surface-initiated ATRP for protein delivery. Journal of Materials Chemistry. 2012; 22:21257-21264.

[92]. Stanley SA, Gagner JE, Damanpour S, Yoshida M, Dordick JS, Friedman JM. Radio-wave heating of iron oxide nanoparticles can regulate plasma glucose in mice. Science. 2012; 336:604608. [PubMed: 22556257]

[93]. Knezevic NZ, Trewyn BG, Lin VS. Functionalized mesoporous silica nanoparticle-based visible light responsive controlled release delivery system. Chem Commun (Camb). 2011; 47:28172819. [PubMed: 21240408]

[94]. Gu Z, Biswas A, Joo K-I, Hu B, Wang P, Tang Y. Probing protease activity by singlefluorescent-protein nanocapsules. Chemical Communications. 2010; 46:6467-6469. [PubMed: 20657917]

[95]. Fomina N, Sankaranarayanan J, Almutairi A. Photochemical mechanisms of light-triggered release from nanocarriers. Advanced drug delivery reviews. 2012; 64:1005-1020. [PubMed: 22386560] 
[96]. Zhou H, Gan X, Liu T, Yang Q, Li G. Electrochemical study of photovoltaic effect of nano titanium dioxide on hemoglobin. Bioelectrochemistry. 2006; 69:34-40. [PubMed: 16386965]

[97]. Paunesku T, Vogt S, Lai B, Maser J, Stojicevic N, Thurn KT, Osipo C, Liu H, Legnini D, Wang Z, Lee C, Woloschak GE. Intracellular distribution of TiO2-DNA oligonucleotide nanoconjugates directed to nucleolus and mitochondria indicates sequence specificity. Nano letters. 2007; 7:596-601. [PubMed: 17274661]

[98]. Song YY, Schmidt-Stein F, Bauer S, Schmuki P. Amphiphilic TiO2 nanotube arrays: an actively controllable drug delivery system. Journal of the American Chemical Society. 2009; 131:42304232. [PubMed: 19317500]

[99]. Balaur E, Macak JM, Taveira L, Schmuki P. Tailoring the wettability of TiO2 nanotube layers. Electrochemistry Communications. 2005; 7:1066-1070.

[100]. Wei YS, Lin SY, Wang SL, Li MJ, Cheng WT. Fourier transform IR attenuated total reflectance spectroscopy studies of cysteine-induced changes in secondary conformations of bovine serum albumin after UV-B irradiation. Biopolymers. 2003; 72:345-351. [PubMed: 12949825]

[101]. Kerwin BA, Remmele RL. Protect from light: Photodegradation and protein biologics. Journal of Pharmaceutical Sciences. 2007; 96:1468-1479. [PubMed: 17230445]

[102]. Kim Y, Kim Sung H. Tanyeri M, Katzenellenbogen John A. Schroeder Charles M. Dendrimer Probes for Enhanced Photostability and Localization in Fluorescence Imaging. Biophysical Journal. 2013; 104:1566-1575. [PubMed: 23561533]

[103]. Luo L, Guo Y, Yang J, Liu Y, Chu S, Kong F, Wang Y, Zou Z. An efficient visible light controlled protein delivery system. Chem Commun (Camb). 2011; 47:11243-11245. [PubMed: 21931893]

[104]. Schroeder A, Goldberg MS, Kastrup C, Wang Y, Jiang S, Joseph BJ, Levins CG, Kannan ST, Langer R, Anderson DG. Remotely activated protein-producing nanoparticles. Nano letters. 2012; 12:2685-2689. [PubMed: 22432731]

[105]. Tang H, Kobayashi H, Niidome Y, Mori T, Katayama Y, Niidome T. CW/pulsed NIR irradiation of gold nanorods: Effect on transdermal protein delivery mediated by photothermal ablation. J Control Release. 2013; 171:178-183. [PubMed: 23863449]

[106]. De Rossi DE, Chiarelli P, Buzzigoli G, Domenici C, Lazzeri L. Contractile behavior of electrically activated mechanochemical polymer actuators. ASAIO transactions / American Society for Artificial Internal Organs. 1986; 32:157-162. [PubMed: 3778704]

[107]. Kwon IC, Bae YH, Kim SW. Electrically erodible polymer gel for controlled release of drugs. Nature. 1991; 354:291-293. [PubMed: 1956379]

[108]. Tomer R, Dimitrijevic D, Florence AT. Electrically controlled release of macromolecules from cross-linked hyaluronic acid hydrogels. J Control Release. 1995; 33:405-413.

[109]. Kie Shim J, Ryong Oh S, Bong Lee S, Cho KM. Preparation of hydrogels composed of poly(vinyl alcohol) and polyethyleneimine and their electrical response. Journal of Applied Polymer Science. 2008; 107:2136-2141.

[110]. Jensen M, Birch Hansen P, Murdan S, Frokjaer S, Florence AT. Loading into and electrostimulated release of peptides and proteins from chondroitin 4-sulphate hydrogels. Eur J Pharm Sci. 2002; 15:139-148. [PubMed: 11849910]

[111]. Chorny M, Fishbein I, Forbes S, Alferiev I. Magnetic nanoparticles for targeted vascular delivery. IUBMB life. 2011; 63:613-620. [PubMed: 21721100]

[112]. Huang X, Meng X, Tang F, Li L, Chen D, Liu H, Zhang Y, Ren J. Mesoporous magnetic hollow nanoparticles-protein carriers for lysosome escaping and cytosolic delivery. Nanotechnology. 2008; 19:445101. [PubMed: 21832718]

[113]. Huang Z, Tang F. Preparation, structure, and magnetic properties of mesoporous magnetite hollow spheres. Journal of colloid and interface science. 2005; 281:432-436. [PubMed: 15571699]

[114]. Chorny M, Hood E, Levy RJ, Muzykantov VR. Endothelial delivery of antioxidant enzymes loaded into non-polymeric magnetic nanoparticles. J Control Release. 2010; 146:144-151. [PubMed: 20483366] 
[115]. Cho MH, Lee EJ, Son M, Lee JH, Yoo D, Kim JW, Park SW, Shin JS, Cheon J. A magnetic switch for the control of cell death signalling in in vitro and in vivo systems. Nat Mater. 2012; 11:1038-1043. [PubMed: 23042417]

[116]. Lee KW, Yoon JJ, Lee JH, Kim SY, Jung HJ, Kim SJ, Joh JW, Lee HH, Lee DS, Lee SK. Sustained release of vascular endothelial growth factor from calcium-induced alginate hydrogels reinforced by heparin and chitosan. Transplantation proceedings. 2004; 36:2464-2465. [PubMed: 15561282]

[117]. Ferrara KW. Driving delivery vehicles with ultrasound. Advanced drug delivery reviews. 2008; 60:1097-1102. [PubMed: 18479775]

[118]. Di J, Price J, Gu X, Jiang X, Jing Y, Gu Z. Ultrasound-Triggered Regulation of Blood Glucose Levels Using Injectable Nano-Network. Advanced Healthcare Materials. 2013 n/a-n/a.

[119]. Slowing, Vivero-Escoto JL, Wu CW, Lin VS. Mesoporous silica nanoparticles as controlled release drug delivery and gene transfection carriers. Adv Drug Deliv Rev. 2008; 60:1278-1288. [PubMed: 18514969]

[120]. Cheng R, Meng F, Deng C, Klok HA, Zhong Z. Dual and multi-stimuli responsive polymeric nanoparticles for programmed site-specific drug delivery. Biomaterials. 2013; 34:3647-3657. [PubMed: 23415642]

[121]. Zhang Z, Chen L, Zhao C, Bai Y, Deng M, Shan H, Zhuang X, Chen X, Jing X. Thermo- and pH-responsive HPC-g-AA/AA hydrogels for controlled drug delivery applications. Polymer. 2011; 52:676-682.

[122]. Wang L, Liu M, Gao C, Ma L, Cui D. A pH-, thermo-, and glucose-, triple-responsive hydrogels: Synthesis and controlled drug delivery. Reactive and Functional Polymers. 2010; 70:159-167.

[123]. Gu Z, Yan M, Hu B, Joo KI, Biswas A, Huang Y, Lu Y, Wang P, Tang Y. Protein nanocapsule weaved with enzymatically degradable polymeric network. Nano letters. 2009; 9:4533-4538. [PubMed: 19995089]

[124]. Wiradharma N, Zhang Y, Venkataraman S, Hedrick JL, Yang YY. Self-assembled polymer nanostructures for delivery of anticancer therapeutics. Nano Today. 2009; 4:302-317.

[125]. Peer D, Karp JM, Hong S, FaroKHzad OC, Margalit R, Langer R. Nanocarriers as an emerging platform for cancer therapy. Nature nanotechnology. 2007; 2:751-760.

[126]. Chou LY, Zagorovsky K, Chan WC. DNA assembly of nanoparticle superstructures for controlled biological delivery and elimination. Nature nanotechnology. 2014; 9:148-155.

[127]. Mo R, Jiang T, DiSanto R, Tai W, Gu Z. ATP-triggered anticancer drug delivery. Nature communications. 2014; 5:3364.

[128]. Liechty WB, Chen RJ, Farzaneh F, Tavassoli M, Slater NKH. Synthetic pH-Responsive Polymers for Protein Transduction. Adv Mater. 2009; 21:3910. [PubMed: 22427722] 

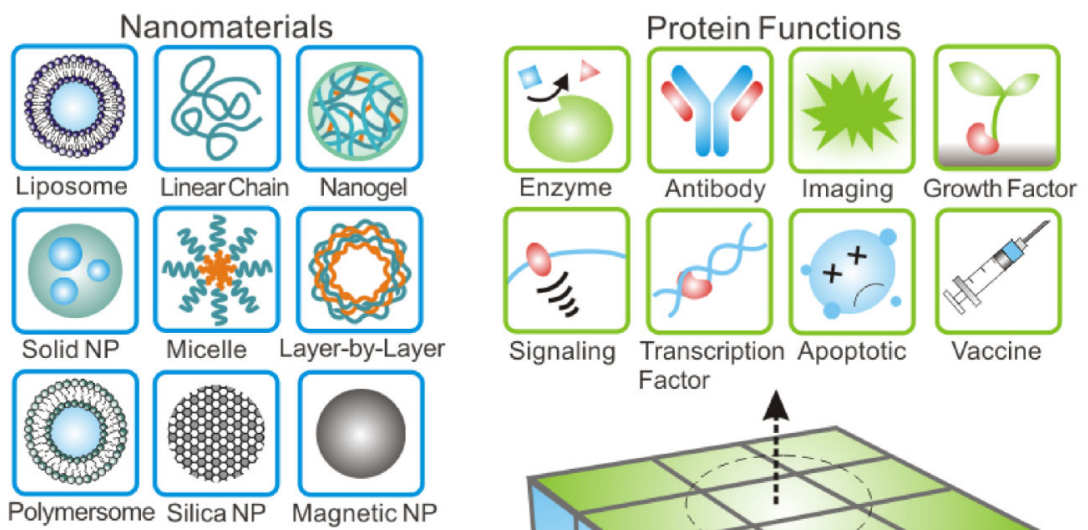

Signaling Transcription Apoptotic Vaccine

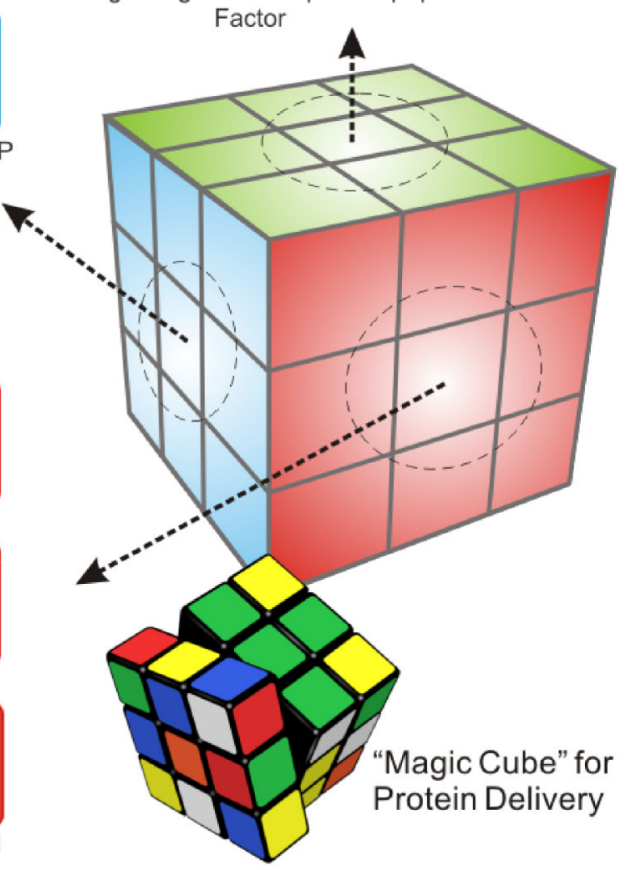

Fig. 1.

Schematic of "Magic Cube" for protein delivery: combination of a variety of triggering mechanisms and carrier formulations for delivery of a broad spectrum of functional proteins. 
A
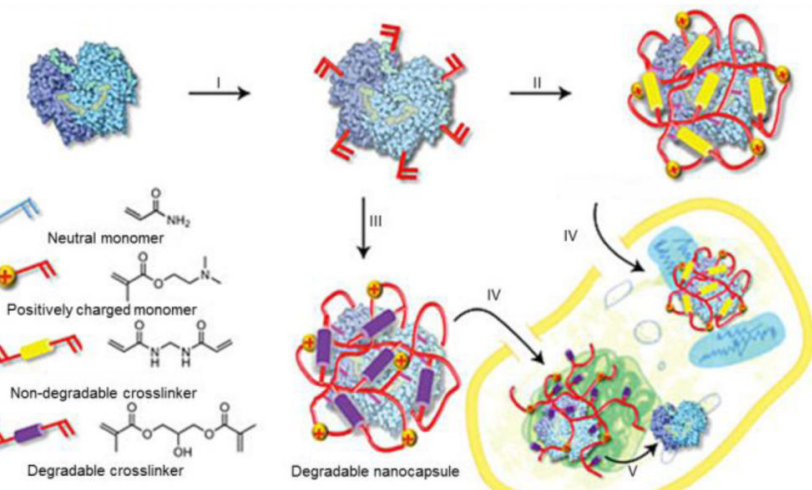

B

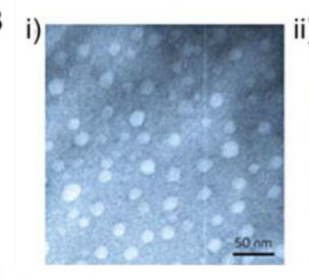

C
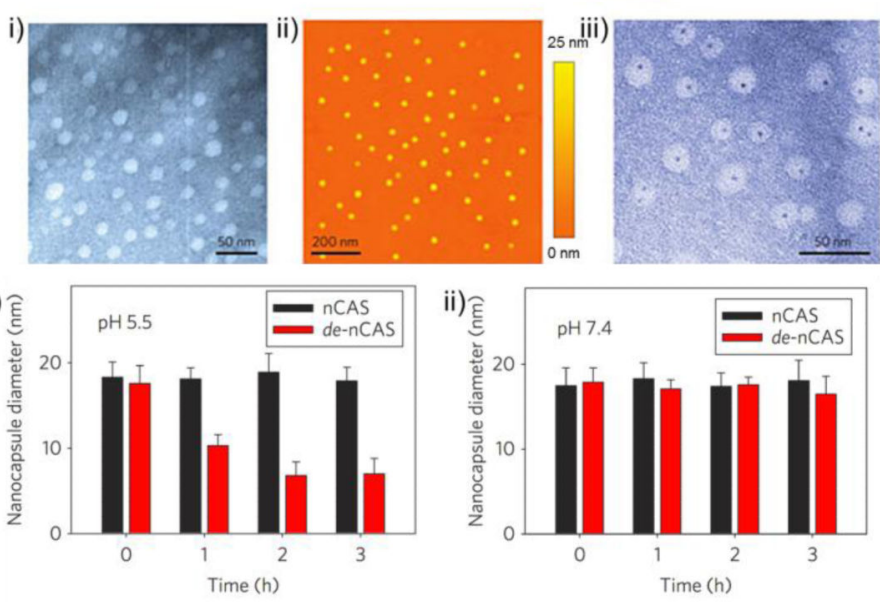

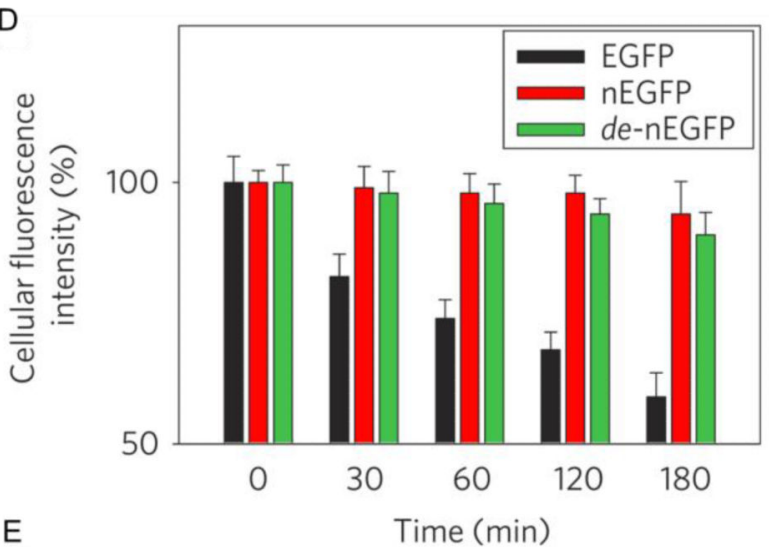

$E$

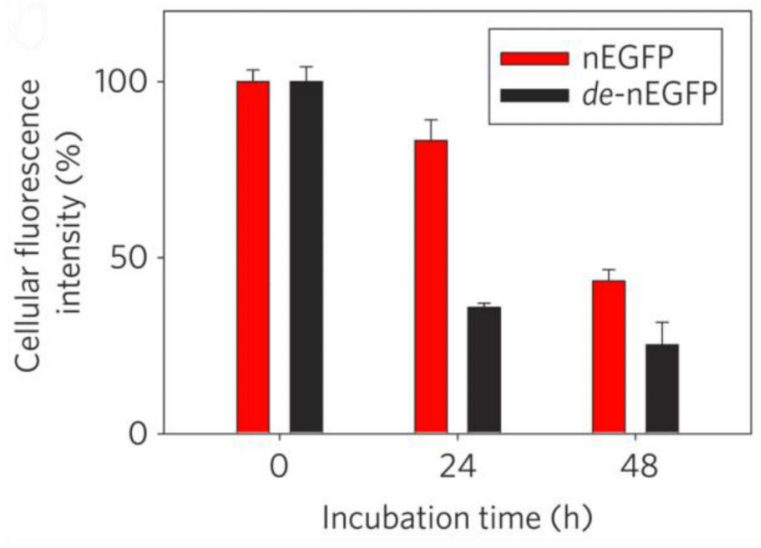

Fig. 2.

(A) Schematic illustration of the synthesis and cellular uptake of cationic single-protein nanocapsules with degradable and non-degradable polymeric shells. (B) (i)(ii) TEM (i) and AFM (ii) images of the HRP nanocapsules; (iii) TEM image of nanocapsules with a goldquantum-dot-labelled HRP core for demonstration of the nanocapsule architecture. (C) Particle sizes of degradable and non-degradable nanocapsules at pH 5.5 (i) and pH 7.4 (ii). (D) Fluorescence intensity of native EGFP, non-degradable EGFP nanocapsules (nEGFP) and degradable EGFP nanocapsules (de-nEGFP) after exposure to $1 \mathrm{mg} \cdot \mathrm{L}^{-1}$ trypsin and achymostrypsin in buffer ( $\mathrm{pH} 7.4,50^{\circ} \mathrm{C}$ ). (E) Fluorescence intensity of HeLa cells incubated with nEGFP or de-nEGFP for $3 \mathrm{~h}$ followed by incubation in fresh media. Adapted with permission from Ref. [34]. 

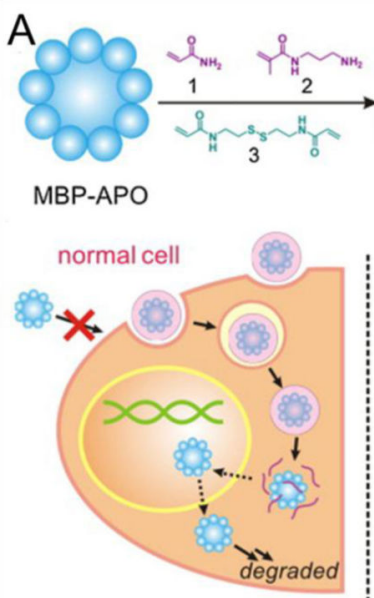

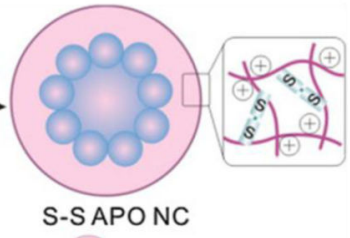

(88) cancer cell

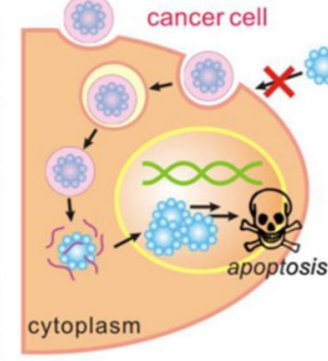

B

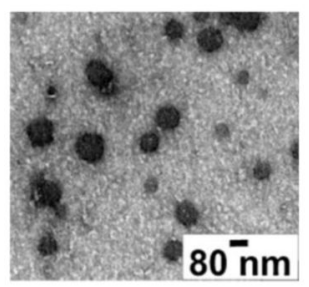

C

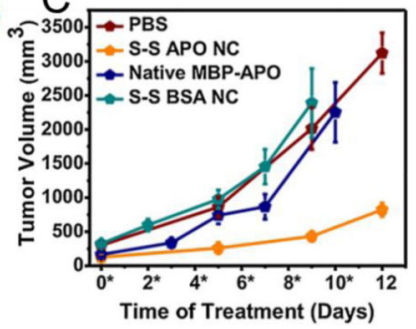

Fig. 3.

Redox-responsive polymeric nanocapsule for intracellular delivery of tumor-selective apoptin complex: (A) Schematic illustration of degradable apoptin nanocapsules (S-S APO NC) synthesis (upper) and intracellular delivery to induce apoptosis of tumor cells (lower). (B) TEM image of S-S APO NC. (C) Tumor inhibition observed in mice treated by S-S APO NC. Adapted with permission from Ref. [50]. 
A

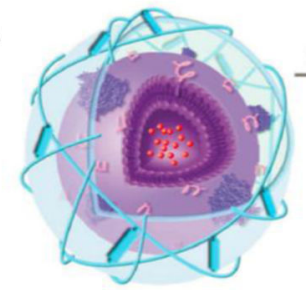

a TRAll $\because$ Dox

† R8H3-C18 RหR EPC

$\sim m-\mathrm{HA} \quad \mathrm{MBA}$

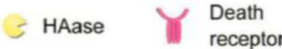

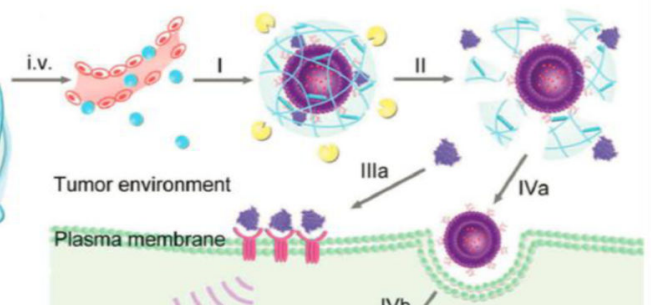

Tumor environment

Plasma membrane

$\mathrm{IVb}$
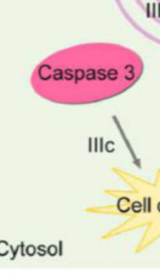

(1)

Cell death

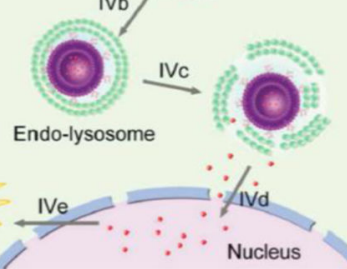

B
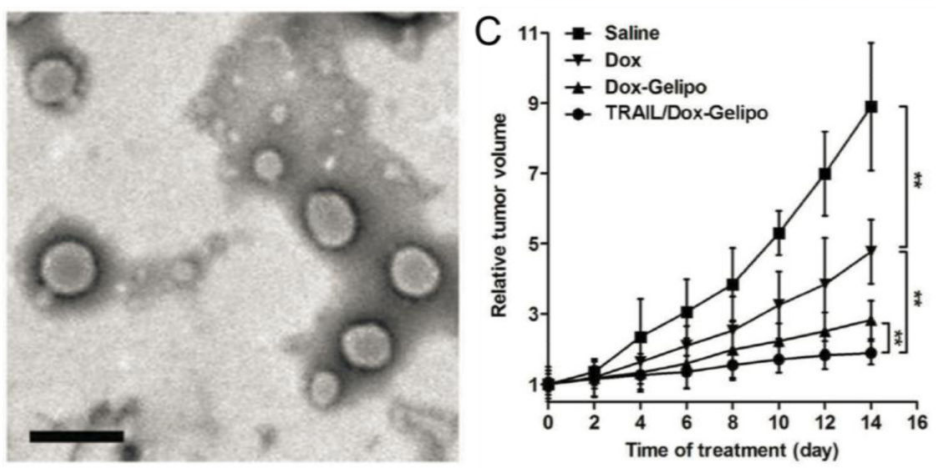

Fig. 4.

(A) Scheme of TRAIL and Dox co-loaded Gelipo (TRAIL/Dox-Gelipo) for sequential and site-specific drug delivery. (B) TEM image of TRAIL/Dox-Gelipo, scale bar: $200 \mathrm{~nm}$. (C) MDA-MB-231 tumor growth curves after intravenous injection of different formulations. Adapted with permission from Ref. [64]. 

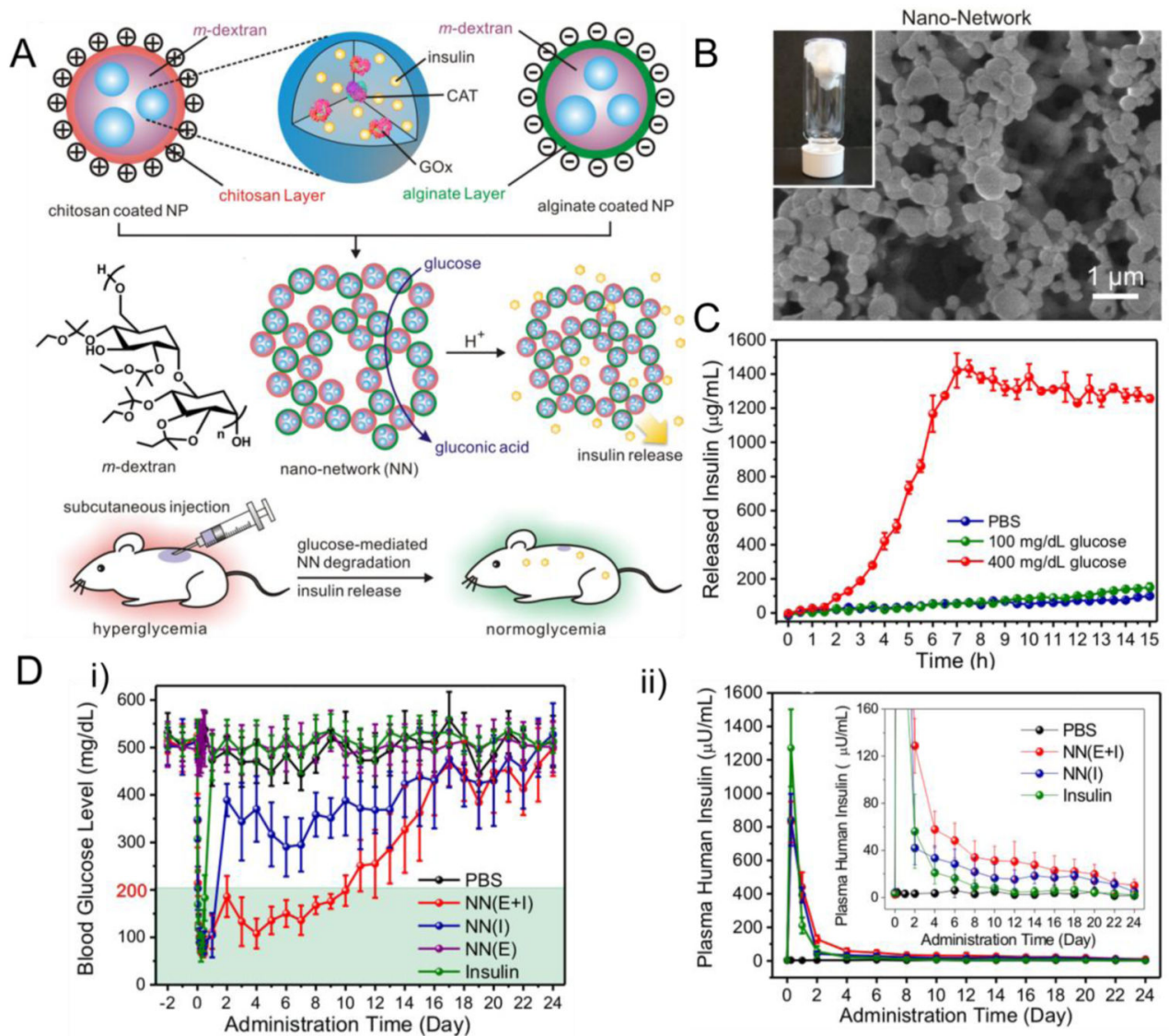

ii)

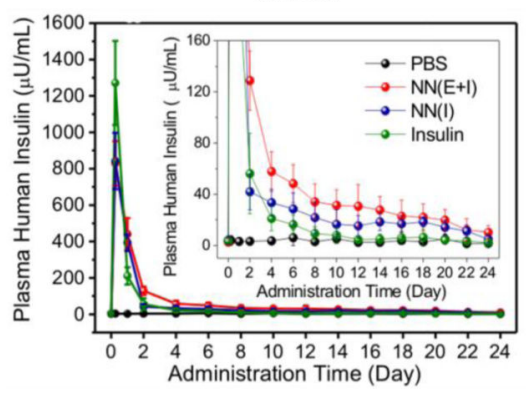

Fig. 5.

(A) Schematic illustration of injectable nano-network for glucose-responsive insulin delivery. (B) SEM image of formed nano-network. (C) In vitro accumulated insulin release from nano-network under different glucose concentrations. (D) In vivo studies of the nanonetwork for type 1 diabetes therapy: blood glucose levels (i) and plasma human insulin concentration (ii) in type 1 diabetic mice injected with $1 \times \mathrm{PBS}$, insulin and enzyme encapsulated nano-network, insulin encapsulated nano-network, enzyme encapsulated nanonetwork, and insulin solution. Adapted with permission from Ref. [70]. 
A
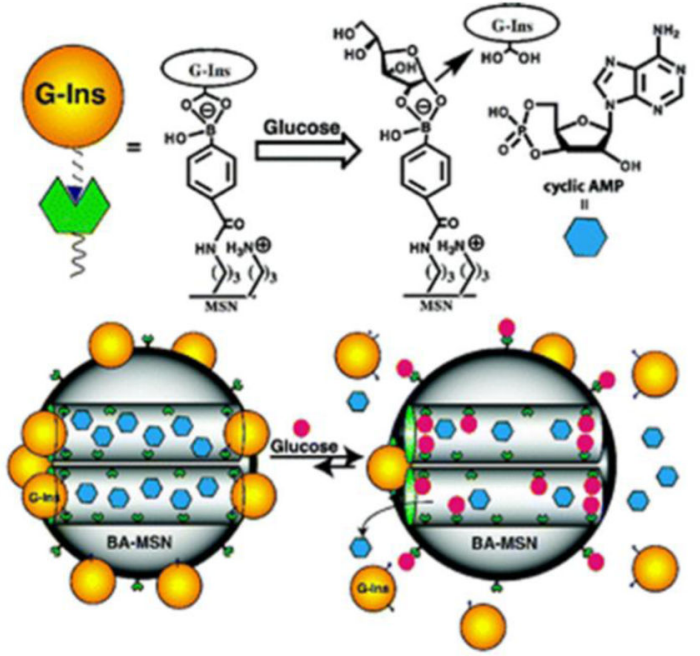

B
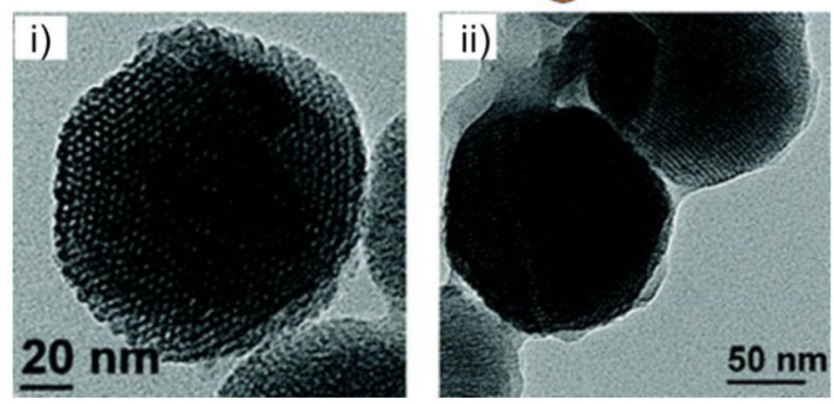

Fig. 6.

MSN-based glucose-responsive system for co-delivery of insulin and cyclic AMP: (A) Schematic illustration of the glucose-responsive co-delivery system; (B) TEM images of boronic acid-functionalized MSN (i) and FITC-G-Ins-capped MSN (ii). Adapted with permission from Ref. [82]. 
A

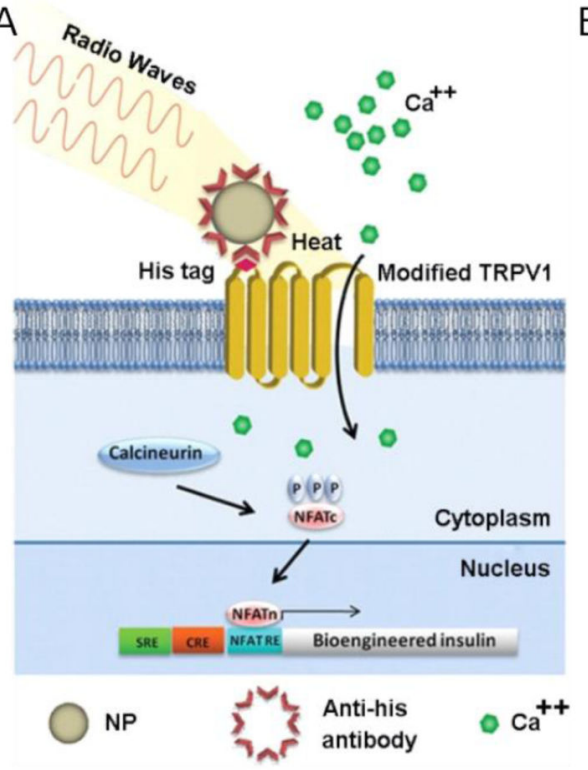

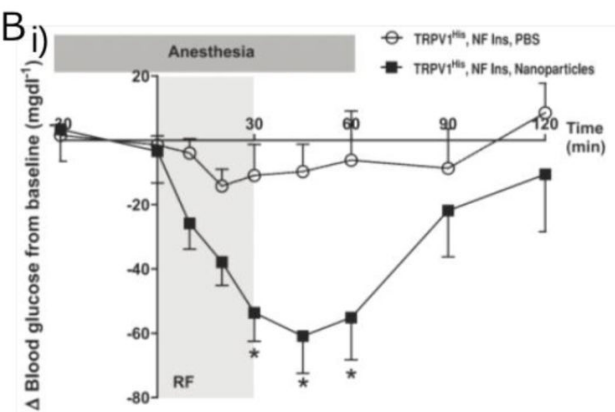

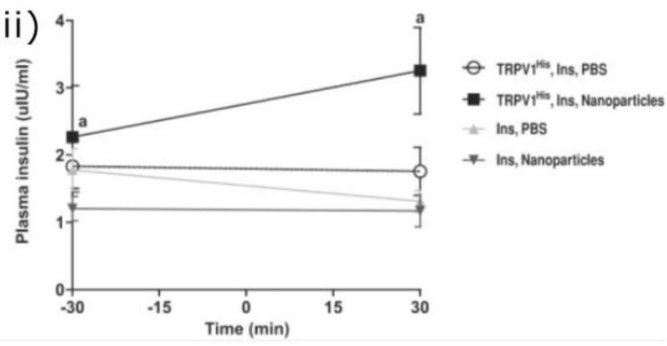

Fig. 7.

Iron oxide nanoparticle based plasma glucose regulation triggered by radio-wave heating: (A) Schematic illustration of cell activation and gene expression induced by iron oxide nanoparticle. (B) Effects of RF treatment on blood glucose (i) and plasma insulin (ii) in PBS and nanoparticle-treated mice with tumors expressing TRPV $1^{\text {His }}$ and calcium-dependent human insulin. Adapted with permission from Ref. [92]. 

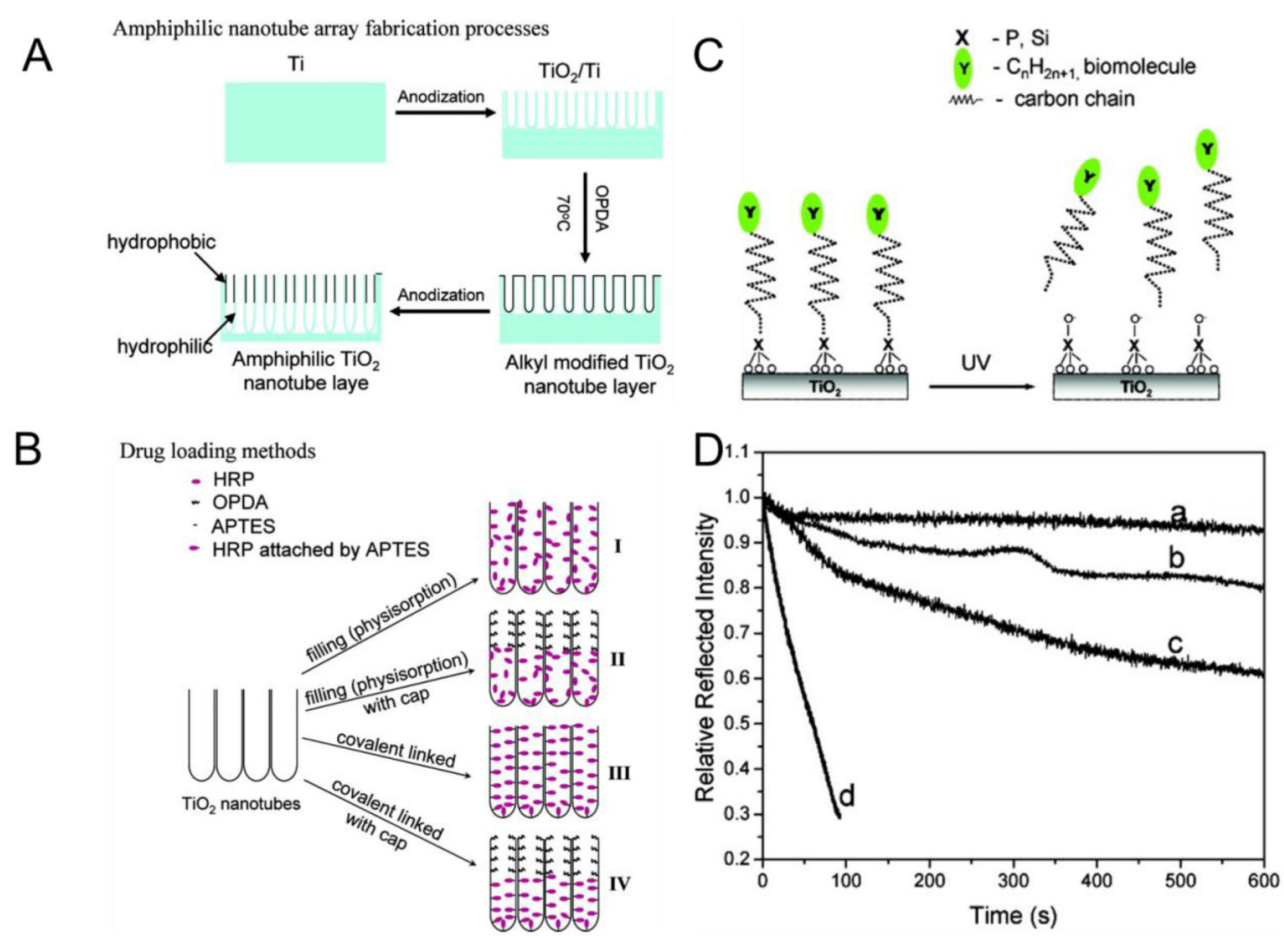

Fig. 8.

UV-responsive amphiphilic $\mathrm{TiO}_{2}$ nanotube arrays for controlled drug delivery: (A) Scheme of amphiphilic TiO2 nanotube layer fabrication. (B) Four methods for HRP loading. (C) Schematic illustration of HRP release under UV illumination. (D) Relative intensity of reflected light over time of HRP loaded $\mathrm{TiO}_{2}$ nanotubes after exposure to PBS without illumination (a), 50\% UV illumination (b), and full UV illumination (c). Curve $d$ shows the release of $\mathrm{HRP}$ from $\mathrm{TiO}_{2}$ nanotubes without surface modification. Adapted with permission from Ref. [98]. 
A

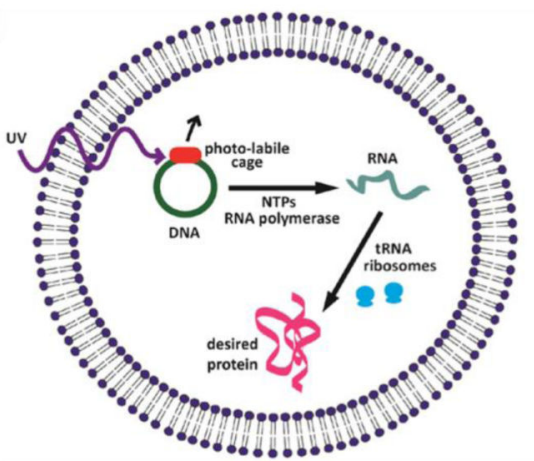

C i)

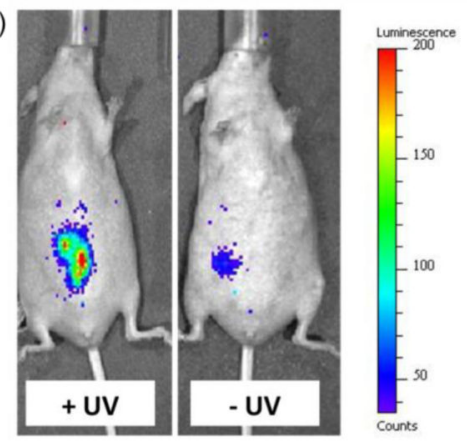

B

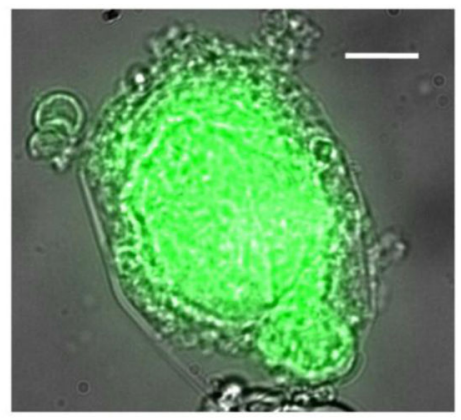

ii)

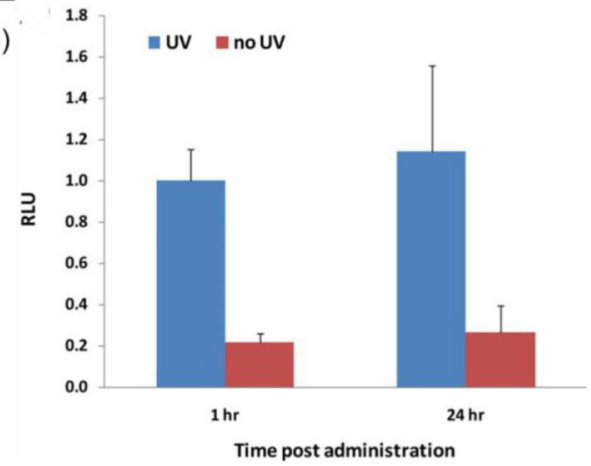

Fig. 9.

Light-triggered protein-producing nanoparticle: (A) Scheme of lipid vesicles encapsulated with cellular machinery responsible for transcription and translation. (B) Overlaid transmitted light and fluorescence images of a GFP-producing particle. (C) Production of luciferase in vivo induced by UV irradiation: (i) bioluminescence imaging of mice injected locally with protein-producing nanoparticles; (ii) quantitation of the bioluminescence imaging shown in (i). Adapted with permission from Ref. [104]. 
A
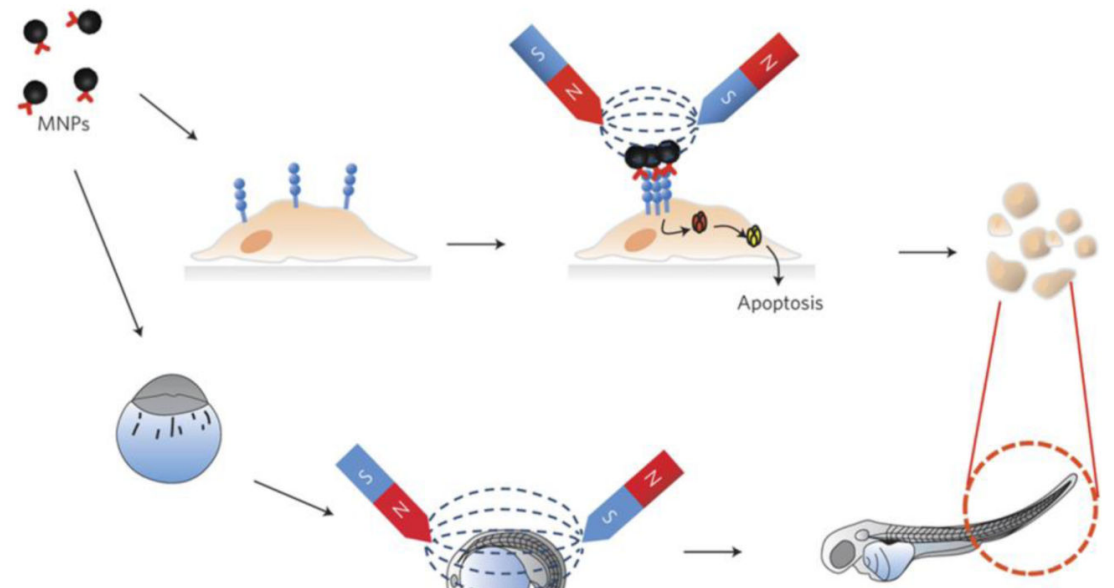

B

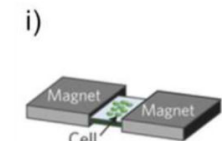

iv)
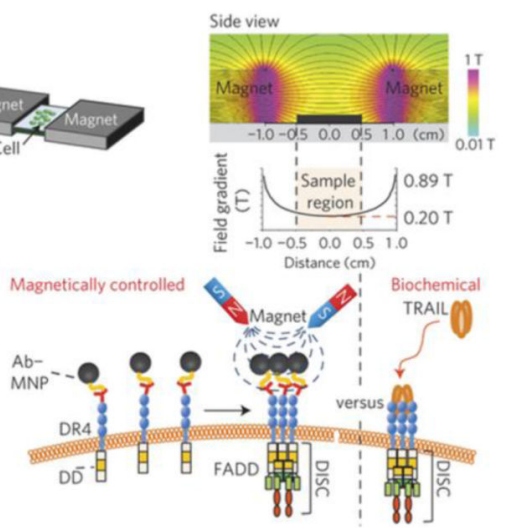

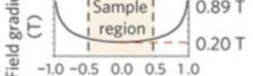

Distance $(\mathrm{cm})$

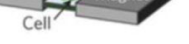

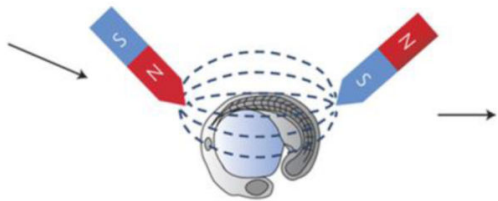

ii)

Before magnetic field After magnetic field

iii)

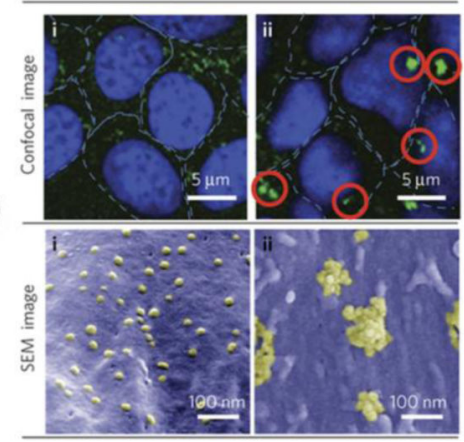

Fig. 10.

(A) Schematic illustration of magnetic switch for apoptosis signaling in vitro and in vivo; (B) (i) magnetic switch set-up for apoptosis signaling; (ii)(iii) confocal microscope (ii) and SEM (iii) images of Ab-MNP (1 pM)-treated DLD-1 cells; (iv) biomimetic magnetic switch for apoptosis signaling induction via receptor aggregation. Adapted with permission from Ref. [115]. 
A i)

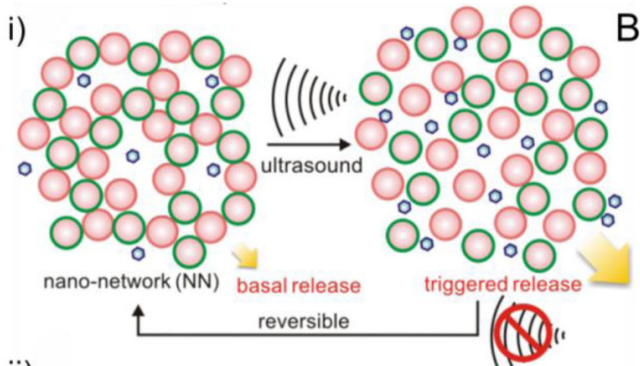

ii)

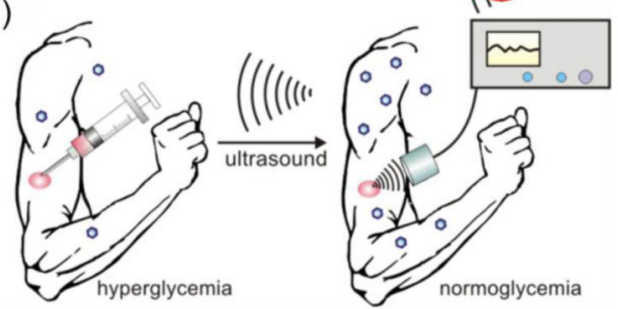

B i)
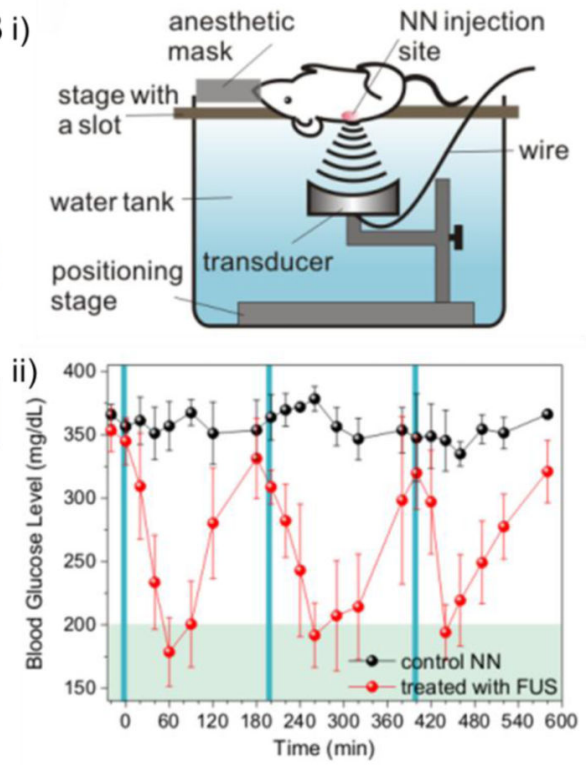

Fig. 11.

(A) Schematic illustration of FUS-mediated insulin delivery: (i) FUS triggered insulin release from nano-network; (ii) noninvasive long-term blood glucose regulation controlled by FUS. (B) FUS-mediated in vivo blood glucose regulation: (i) schematic illustration of experimental apparatus; (ii) blood glucose levels in STZ-induced C57B6 diabetic mice with and w/o FUS treatment: FUS treatment was repeatedly applied three times and the administration windows are represented by the blue solid columns. Adapted with permission from Ref. [118]. 


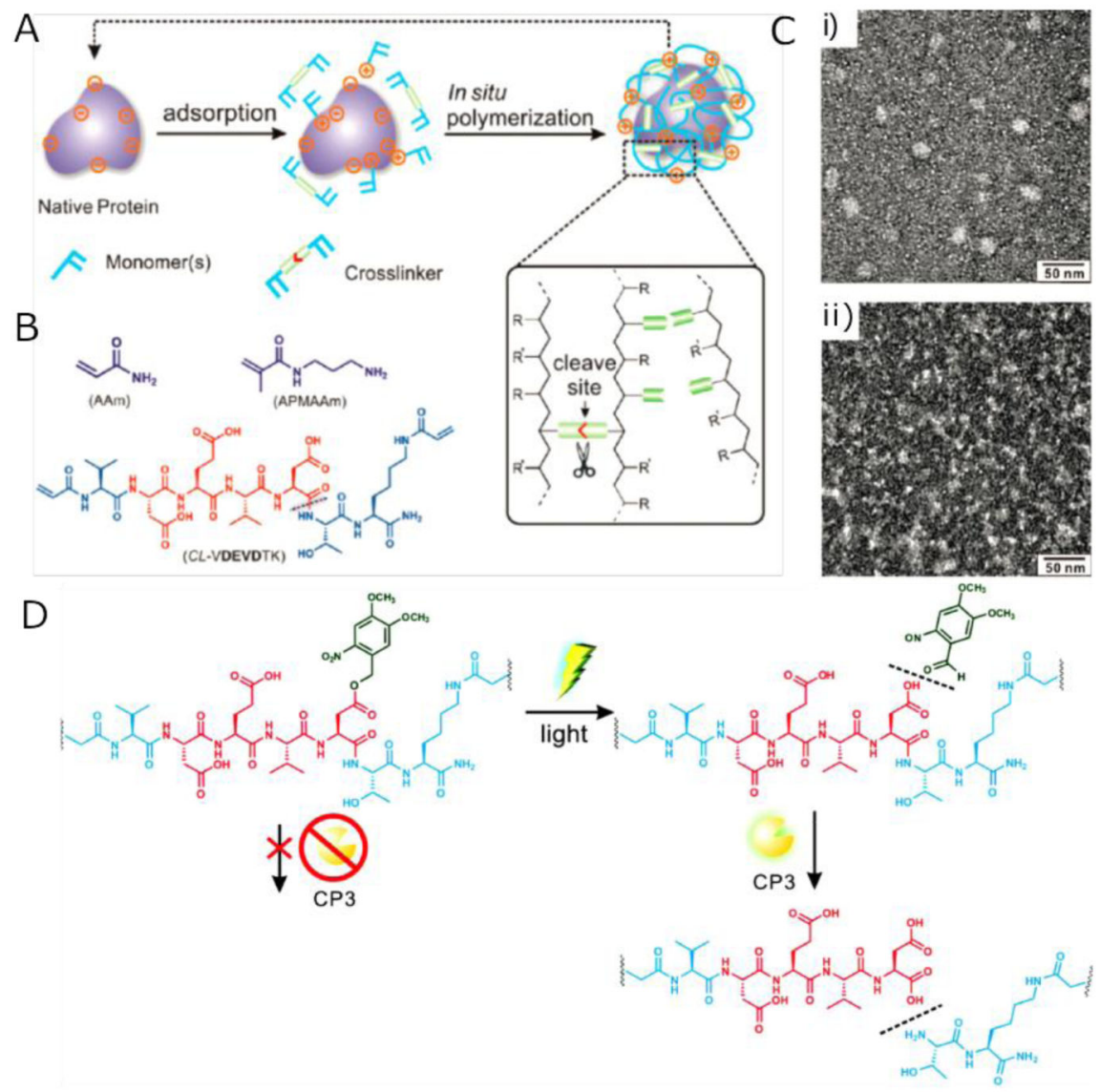

Fig. 12.

(A) Scheme of protein nanocapsule preparation via in situ free-radical polymerization. (B) Typical monomers and cross-linker used in this study. (C) TEM images of fresh CP3 nanocapsules (i) and CP3 nanocapsules after self-degradation (ii). (D) Schematic illustration of the structure and function of the peptide cross-linker CL-VDEVD ${ }_{\mathrm{m}} \mathrm{TK}$. Adapted with permission from Ref. [123] 


\section{Table 1}

Summary of recently reported stimuli-responsive nanomaterial based protein/peptide delivery systems covered in this review

\begin{tabular}{|c|c|c|c|c|c|}
\hline Stimulus & & Nanomaterial & $\begin{array}{l}\text { Model } \\
\text { protein/peptide }\end{array}$ & Target location & Ref \\
\hline \multirow[t]{24}{*}{ Physiological } & $\mathrm{pH}$ & PIC micelles & CytC, IgG & Intracellular: HuH-7 & $\begin{array}{l}{[28,} \\
29]\end{array}$ \\
\hline & & PP-75 & MBP-Apoptin & Intracellular: Saos-2 & {$[128]$} \\
\hline & & $\begin{array}{l}\text { cross-linked PDEAEMA-core/ } \\
\text { PAEMA-shell particles }\end{array}$ & OVA protein & $\begin{array}{l}\text { Intracellular: CD8 }{ }^{+} \\
\text {T-cells }\end{array}$ & {$[32]$} \\
\hline & & TMC-based PEC nanocarriers & R-GAL & Intracellular & {$[33]$} \\
\hline & & polyaspartamide nanocapsules & BSA & Intracellular: NIH-3T3 & {$[14]$} \\
\hline & & single-protein nanocapsules & $\begin{array}{l}\text { EGFP, HRP, } \\
\text { BSA, SOD and } \\
\text { CAS }\end{array}$ & Intracellular & {$[34]$} \\
\hline & & triple-enzyme nanocomplex & $\begin{array}{l}\text { alcohol oxidase } \\
\text { and catalase }\end{array}$ & Serum & {$[35]$} \\
\hline & & $\begin{array}{l}\text { aldehyde-displaying silica } \\
\text { nanoparticles }\end{array}$ & Arginase, GFP & $\begin{array}{l}\text { Intracellular: HepG2, } \\
\text { HeLa and L929 }\end{array}$ & {$[38]$} \\
\hline & & PAAD/PGA hydrogels & insulin & Serum & {$[43]$} \\
\hline & & multi-ion-crosslinked NPs & insulin & Serum & {$[44]$} \\
\hline & & PLA-PEG NP & insulin & Serum & {$[45]$} \\
\hline & Redox & single-protein nanocapsules & CP3 & $\begin{array}{l}\text { Intracellular: HeLa, } \\
\text { MCF-7 and U-87 MG }\end{array}$ & {$[49]$} \\
\hline & & Protein nanocapsules & MBP-APO & $\begin{array}{l}\text { Intracellular: } \\
\text { MDA-MB-231, HeLa, } \\
\text { MCF-7, and HFF }\end{array}$ & {$[50]$} \\
\hline & & $\begin{array}{l}\text { chitosan/poly(L-aspartic } \\
\text { acid) nanocapsules }\end{array}$ & insulin & Intracellular: A549 & {$[51]$} \\
\hline & Enzyme & crosslinked nano matrix & $\begin{array}{l}\text { EGFP, CP3, BSA } \\
\text { and Klf4 }\end{array}$ & $\begin{array}{l}\text { Intracellular: Chinese } \\
\text { hamster ovary (CHO) } \\
\text { cell lines, HeLa and } \\
\text { MEF }\end{array}$ & {$[54]$} \\
\hline & & protein nanocapsules & BSA, VEGF & $\begin{array}{l}\text { Intracellular: } \\
\text { HUVECs }\end{array}$ & {$[56]$} \\
\hline & & PEG hydrogels & BSA, lysozyme & & {$[61]$} \\
\hline & & PEGA hydrogels & BSA & & {$[63]$} \\
\hline & & Gelipo & TRAIL & $\begin{array}{l}\text { Intracellular: } \\
\text { MDA-MB-231 }\end{array}$ & {$[64]$} \\
\hline & Glucose & GOx contained hydrogels & insulin & & [69] \\
\hline & & $\begin{array}{l}\text { acid-degradable polymeric } \\
\text { network }\end{array}$ & insulin & Serum & {$[70]$} \\
\hline & & $\begin{array}{l}\text { enzyme nanocapsule- } \\
\text { integrated } \mathrm{pH} \text {-responsive } \\
\text { microgels }\end{array}$ & insulin & Serum & {$[71]$} \\
\hline & & ConA contained hydrogels & insulin & & {$[77]$} \\
\hline & & $\begin{array}{l}\text { hydrogels based on dextran } \\
\text { methacrylate derivative and } \\
\text { ConA }\end{array}$ & insulin & & {$[79]$} \\
\hline
\end{tabular}




\begin{tabular}{|c|c|c|c|c|c|}
\hline \multirow[t]{3}{*}{ Stimulus } & & Nanomaterial & $\begin{array}{l}\text { Model } \\
\text { protein/peptide }\end{array}$ & Target location & Ref \\
\hline & & PBOx & insulin & & {$[80]$} \\
\hline & & BA-MSN & insulin & Serum & {$[82]$} \\
\hline \multirow{15}{*}{ External } & \multirow[t]{4}{*}{ Temperature } & $\begin{array}{l}\text { chitosan-PEG copolymer based } \\
\text { hydrogels }\end{array}$ & BSA & & {$[88]$} \\
\hline & & PNIPAAm hydrogels & insulin, BSA & & {$[90]$} \\
\hline & & PNIPAAm-grafted PPCL films & BSA & & [91] \\
\hline & & FeNPs & insulin & Serum & {$[92]$} \\
\hline & \multirow[t]{4}{*}{ Light } & $\begin{array}{l}\text { amphiphilic } \mathrm{TiO}_{2} \\
\text { nanotubular-structured } \\
\text { nanocarrier }\end{array}$ & HRP & & [98] \\
\hline & & $\mathrm{TiO}_{2}$ nanoparticles & $\mathrm{Hb}$ & & [103] \\
\hline & & lipid based nanoparticles & GFP, luciferase & Serum & [104] \\
\hline & & silica-coated gold nanorods & OVA & Skin & [105] \\
\hline & \multirow[t]{2}{*}{ Electric field } & HA hydrogels & BSA & & [108] \\
\hline & & CS hydrogels & $\begin{array}{l}\text { vasopressin, } \\
\text { aprotinin, } \\
\text { lysozyme and } \\
\text { BSA }\end{array}$ & & [110] \\
\hline & \multirow[t]{3}{*}{ Magnetic force } & AMMHs & BSA & Intracellular: A375 & [112] \\
\hline & & fatty acid calcium salt & $\begin{array}{l}\text { antioxidant } \\
\text { enzymes, SOD } \\
\text { and catalase }\end{array}$ & $\begin{array}{l}\text { Intracellular: BAEC } \\
\text { and HUVEC }\end{array}$ & {$[114]$} \\
\hline & & Ab-MNPs & DR4 & Intracellular: DLD-1 & [115] \\
\hline & \multirow{2}{*}{$\begin{array}{l}\text { Mechanical } \\
\text { force }\end{array}$} & calcium alginate hydrogels & VEGF & & [116] \\
\hline & & PLGA nano-network & insulin & Serum & [117] \\
\hline \multirow{3}{*}{$\begin{array}{l}\text { Dual and } \\
\text { Multi-stimuli }\end{array}$} & $\mathrm{pH} /$ temperature & HPC-g-AA/AA hydrogels & BSA & & [121] \\
\hline & $\begin{array}{l}\mathrm{pH} / \text { temperature } \\
\text { and glucose }\end{array}$ & $\begin{array}{l}\text { P(DMAEMA-co-AAPBA) } \\
\text { hydrogels }\end{array}$ & BSA & & [122] \\
\hline & Enzyme/light & polymeric nanocapsules & $\mathrm{CP} 3$ & Intracellular: Hela & [123] \\
\hline
\end{tabular}

